\title{
Choosing Your Neighbors: Networks of Diffusion in International Relations
}

\section{Citation}

Zhukov, Yuri M. and Brandon M Stewart. Forthcoming. Choosing your neighbors: Networks of diffusion in international relations. International Studies Quarterly.

\section{Published Version}

http://www.wiley.com/bw/journal.asp?ref=0020-8833

\section{Permanent link}

http://nrs.harvard.edu/urn-3:HUL.InstRepos:5142122

\section{Terms of Use}

This article was downloaded from Harvard University's DASH repository, and is made available under the terms and conditions applicable to Open Access Policy Articles, as set forth at http:// nrs.harvard.edu/urn-3:HUL.InstRepos:dash.current.terms-of-use\#OAP

\section{Share Your Story}

The Harvard community has made this article openly available.

Please share how this access benefits you. Submit a story.

\section{Accessibility}




\title{
Choosing Your Neighbors: Networks of Diffusion in International Relations*
}

\author{
Yuri M. Zhukov and Brandon M. Stewart ${ }^{\dagger}$ \\ Forthcoming in International Studies Quarterly
}

July 21, 2011

\begin{abstract}
In examining the diffusion of social and political phenomena like regime transition, conflict, and policy change, scholars routinely make choices about how proximity is defined and which neighbors should be considered more important than others. Since each specification offers an alternative view of the networks through which diffusion can take place, one's decision can exert a significant influence on the magnitude and scope of estimated diffusion effects. This problem is widely recognized, but is rarely the subject of direct analysis. In international relations research, connectivity choices are usually ad hoc, driven more by data availability than by theoreticallyinformed decision criteria. We take a closer look at the assumptions behind these choices, and propose a more systematic method to asses the structural similarity of two or more alternative networks, and select one that most plausibly relates theory to empirics. We apply this method to the spread of democratic regime change, and offer an illustrative example of how neighbor choices might impact predictions and inferences in the case of the 2011 Arab Spring.
\end{abstract}

Word count: 8,795 (without references), 10,626 (with references)

${ }^{*}$ Previous versions of this paper were presented at the 2010 International Studies Association Annual Meeting in New Orleans, LA and the 2010 American Political Science Association Annual Meeting in Washington, DC. We wish to acknowledge useful comments and insights from Abraham Flaxman, Gary King, Patrick Lam, Miya Woolfalk, Paul Hensel, Andrew Thomas, Dale Thomas and seminar participants at the Institute for Quantitative Social Science. We are particularly grateful to Gary King for inspiring the Conflicting Neighbor Problem. Remaining errors are our own. We also want to thank Kristian Skrede Gleditsch and Michael D. Ward for making complete replication data and code easily available for use. This draft is meant to be printed in color. Replication materials and maps are currently available upon request and will be posted to the authors' Dataverse upon publication.

${ }^{\dagger}$ Ph.D. Candidate, Department of Government, Institute for Quantitative Social Science, 1737 Cambridge St. Harvard University, Cambridge, MA 02138. The authors can be contacted at zhukov@fas.harvard.edu and bstewart@fas.harvard.edu. 
Who are a country's neighbors? On a gut level, the answer might seem obvious: a country's neighbors are the ones closest to it. Yet choosing an appropriate proximity measure can be a difficult task, and one which can influence empirical findings in decisive ways (Stetzer, 1982; Bavaud, 1998; Anselin, 2002; Lee, 2009). A growing literature in international relations has highlighted the importance of geographical proximity to the diffusion of social and political phenomena, such as regime transitions (Starr, 1991; O'Loughlin et al., 1998; Gleditsch and Ward, 2000; Starr and Lindborg, 2003; Gleditsch and Ward, 2006), conflict (Murdoch and Sandler, 2002; Salehyan and Gleditsch, 2006; Buhaug and Gleditsch, 2008; Gleditsch et al., 2008; Salehyan, 2008), foreign economic policies (Simmons and Elkins, 2004), bilateral investment treaties (Elkins et al., 2006), defense policies (Barkley, 2008), government expenditure (Lee and Strang, 2006) and capital taxation (Cao, 2010). ${ }^{1}$ Most studies define proximity by shared borders, distances between capitals, or some combination of the two. Others insist that the connective structure of the international system is not necessarily geographic, and is based instead on mutual participation in institutions like trade, intergovernmental organizations and alliances (Cao, 2009; Greenhill et al., 2009; Cao, 2010; Greenhill, 2010; Lazer, 2011; Strebel, 2011). Yet few guidelines exist as to which network specification fits a particular type of research question, or - once a theoretically appropriate measure is identified - how one's choice might influence one's results.

This gap is consequential for both academic research and policy analysis. Diffusion has long been a fundamental concept in foreign policy decision-making: from the "domino theory" of communist expansion during the Cold War, to more recent debates about the spread of democracy in Eastern Europe, and the potential spillover of protests and revolutions across the Arab world. ${ }^{2}$ In order to accurately model and predict these and other diffusion processes, it is essential to first make sense of what we mean by space, proximity and the connections between states.

In international relations, connectivity choices (what constitutes a neighbor) and spatial weights (how neighbors affect each other) are often assumed without theoretical justification. The sensitivity of results to these assumptions is widely acknowledged, but most attempts at a systematic investigation in an international relations context have been limited to differences within these choices rather than between them. For instance, there have been several notable studies of sensitivity across different distance thresholds or different fixed numbers of neighbors (O'Loughlin and Anselin, 1991; Gleditsch and Ward, 2007; Cao, 2010; Plümper and Neumayer, 2010; Seldadyo et al., 2010). ${ }^{3}$ While within-measure sensitivity is important, it becomes relevant only after one answers

\footnotetext{
${ }^{1}$ Franzese and Hays have an extremely comprehensive reference list of the political science literature using spatialmodeling at http://www-personal.umich.edu/ franzese/FranzeseHays. Interdependence. IPSA. References .pdf

${ }^{2}$ The gap is closing; Leeson and Dean (2009) published a recent article re-examining the Democratic Domino Theory using spatial econometrics.

${ }^{3}$ It is worth clarifying our contribution in the context of three of these studies. Cao (2010) offers an excellent applied example of many of the recommendations that we independently developed. He tests the sensitivity of distance thresholds, and experiments with non-geographic measures of distance in pursuit of his substantive point. Whereas his focus on taxation is primary with an ancillary focus on general practice, we are primarily interested in general practice with a substantive example for demonstration purposes. The Gleditsch and Ward (2007) monograph
} 
more fundamental questions of what topological space the units occupy, how distance is defined on that space, and what criterion is used to translate these distances into pairwise ties. Each choice offers a distinct view of the networks through which diffusion can take place, and it can be difficult to assess which specifications are interchangeable and which are not. In this paper, we endeavor to frame the problem, and propose a procedure to adjudicate between competing definitions of neighborhood. In contrast to the current norm of imposing an arbitrary network specification $e x$ ante, we recommend a theoretically-informed enumeration of multiple candidates, followed by an ex post evaluation of their structural similarity and relative statistical and predictive performance.

Our paper is organized as follows. First, we review how diffusion has been treated in recent international relations studies. Second, we introduce the Conflicting Neighbor Problem and how it manifests itself in practice. We then propose a three-step solution to the problem, and apply it to a reanalysis of a prominent model of democratic diffusion (Gleditsch and Ward, 2006) and a simulation of the 2011 Arab Spring.

\section{Diffusion in International Relations}

There have been two primary applications of spatial data analysis to international relations research. The first, and most common, approach has been to relate proximity to the properties of dyads, such as the level of bilateral trade, cooperation or the incidence and duration of militarized disputes and other forms of conflict. In international political economy, proximity is often used as a component variable in a gravity model, where bilateral trade flows are modeled as a function of the relative sizes and distances between two units (Gowa and Mansfield, 2004; Goldstein et al., 2007). In international security, proximity is often incorporated into opportunity/willingness models of conflict, where proximate states are expected to be more willing to go to war with each other, while opportunities to engage in conflict are expected to decline with distance (Siverson and Starr, 1991; Starr and Thomas, 2005). The most frequently used measure of proximity in this literature is border contiguity (Beck et al., 2000; Lemke and Reed, 2001; Gartzke et al., 2001; Leeds, 2003; Reiter and Stam, 2003; Rasler and Thompson, 2006), while some studies also include ordinal contiguity "scores" (Slantchev, 2004), centroid-to-centroid distances (Goldstein et al., 2007) and capital-to-capital distances (Chiozza, 2002; Clark and Regan, 2003; Dorussen, 2006; Krustev, 2006). ${ }^{4}$ While voluminous, most of this literature treats geography as a control variable of only secondary theoretical interest.

The second application - and the focus of our current study - is diffusion, a concept grounded the notion that "everything is related to everything else, but near things are more related than distant

provides a very useful reference on the estimation of spatial methods. It however, does not give much practical advice on the theoretical choices necessary for estimation which is our focus here. Plümper and Neumayer (2010) provides an excellent overview of the specification of spatial models. We strongly believe all three of these pieces should be read in concert by the applied researcher looking to use spatial models.

${ }^{4}$ The Correlates of War definition of contiguity - the one used most frequently in this literature - provides five levels of contiguity: direct land contiguity and four levels of contiguity by water (Stinnett et al., 2002). 
things" (Tobler, 1970). Unlike the dyadic trade and conflict literature, diffusion studies typically treat spatial dependence as the quantity of central interest. Here, social and political phenomena are seen as clustering in space, and the individual characteristics of a state are expected to exhibit some similarity to those of its neighbors (i.e.: a country located in a democratic region is more likely to become a democracy than one located in an autocratic region). To estimate the magnitude and scope of spillover effects, scholars in this field often employ a spatially lagged dependent variable, such as the average level of democracy in neighboring states or a binary indicator that at least one neighbor is experiencing a civil war. ${ }^{5}$ This field has been quite heterogeneous in its network specifications: authors have identified neighbors by common borders (Starr and Lindborg, 2003; Simmons and Elkins, 2004; Barkley, 2008), length of borders (Murdoch and Sandler, 2002), intercapital distances (Lee and Strang, 2006; Bach and Newman, 2010), regional fixed effects (Pevehouse, 2002), and common borders with a "snap distance," which allows boundary points to be a short distance from one another rather than directly contiguous (Gleditsch and Ward, 2000, 2006; Beck et al., 2006; Buhaug and Gleditsch, 2008; Salehyan and Gleditsch, 2006; Gleditsch et al., 2008).

Rarely, however, are neighbor definitions and their respective tuning parameters - such as the number of neighbors included in the lagged term or the extent of the snap distance - motivated by theoretical considerations about the networks through which a particular type of diffusion takes place. A theoretically informed choice rests on one's answers to two questions. First, what signal must be transmitted for a particular type of diffusion to take place? For the contagion of civil war, this might be combatants, ethnic kin or refugees. For the diffusion of policy, this might be information about successful practices or norms. Second, what is the network through which this signal is most likely to travel? If we assume signals to follow lowest-cost paths, we might expect weapons traffickers to choose illegal border crossing over commercial air travel from capital to capital, though the opposite may be true for diplomats and activists. Further still, we might believe that the pathways of certain types of diffusion are not geographic at all (Beck et al., 2006). Any pairwise relationship can in principle be seen as a measure of proximity. Ethic or cultural ties (Simmons and Elkins, 2004), bilateral trade (Greenhill et al., 2009), joint membership in intergovernmental organizations (Cao, 2009; Greenhill, 2010), and military alliances (Hammarstrom and Heldt, 2002) are just four examples among many. ${ }^{6}$ Some of these networks surely overlap; others may represent separate and independent pathways. How might one assess the degree of similarity between these measures, and arbitrate between them in a systematic way?

\footnotetext{
${ }^{5} \mathrm{~A}$ spatially lagged variable is the cross-product of the weights matrix $\mathbf{W}$ and a vector of observed values $\mathbf{y}$. It can be interpreted as a weighted sum of neighboring values.

${ }^{6}$ For a different approach to network methods in IR see Hafner-Burton et al. (2009).
} 


\section{The Conflicting Neighbor Problem}

A network specification is the outcome of three decisions: (1) the choice of a topological space, (2) the choice of a distance or proximity function defined on that space, and (3) the choice of a connectivity criterion for the distance metric. The Conflicting Neighbor Problem (CNP) lies in the uncertainty of this network specification process. More than one type of topological space may contain the same set of objects; more than one distance function may be defined on the same space; more than one connectivity criterion may be defined for the same distance metric. Even in a relatively simple applied setting like IR, where the universe of objects is well-defined and the relations between them well-catalogued, permutations of these three choices are potentially innumerable. This uncertainty - and the resulting potential for conflict and overlap between specifications - can render elusive the goal of identifying the "true" network of diffusion.

Consider a set of $n$ objects, in our case states in the international system. The topological space $S$ occupied by these objects may be a geographical map, a Cartesian coordinate system, a network of international trade, or any other set for which a notion of distance between objects can be defined. Given $S$, we may define a distance function $d$, which satisfies the following metric properties for all $i, j, k \in S: d(i, j) \geq 0$ (non-negativity), $d(i, j)=d(j, i)$ (symmetry), $d(i, i)=0$ (reflexivity), and $d(i, j) \leq d(i, k)+d(k, j)$ (triangular inequality). The distance function $d$ provides a measure of the "nearness" of two objects situated in space $S$, such that $d(i, j)$ approaches zero as two objects move closer together, and infinity as they move farther apart. Alternatively, we may define a proximity function $p(i, j)$ on $S$, which approaches infinity as two objects move closer together, and zero as they move farther apart. ${ }^{7}$ The number of kilometers between capital cities would be one distance metric in geographical space; the volume of bilateral trade would be a proximity measure in international economic space.

Connectivity criteria link the distance or proximity functions to some categorical definition of neighborhood. In a simple thresholding case with search radius $r$, a connectivity criterion may be $d(i, j)<r$ (e.g. two countries are connected if the distance between their capitals is less than $r \mathrm{~km}$ ) or $p(i, j)>r$ (e.g. if the volume of bilateral trade is greater than $r$ dollars). Pairwise connections between objects are expressed with an $n \times n$ connectivity matrix $\mathbf{C}$, where a cell $\mathbf{c}(i, j)=1$ if objects $i$ and $j$ are "connected" according to some connectivity criterion $\mathbf{c}$, and $\mathbf{c}(i, j)=0$ otherwise.

The CNP occurs when, for the same pair of objects $i, j$ and two or more network specifications $m \in M$, the two objects are considered neighbors under one specification, but not the other. Given two network specifications $m=1,2$, their respective graphs are said to be in perfect conflict if $\mathbf{c}_{1}(i, j) \neq \mathbf{c}_{2}(i, j)$ for all $i, j \in\{1, \ldots, n\}$, and in perfect agreement if $\mathbf{c}_{1}(i, j)=\mathbf{c}_{2}(i, j)$ for all $i, j \in\{1, \ldots, n\}$. They are in partial conflict (or agreement) if both $\mathbf{c}_{1}(i, j) \neq \mathbf{c}_{2}(i, j)$ and

\footnotetext{
${ }^{7}$ Assuming for illustrative purposes a normalized distance bounded by the unit interval $0 \leq d(i, j) \leq 1$, we can define the relationship between distance $d$ and proximity $p$ as $d(i, j)=1-p(i, j)$. Although some of the inequalities are flipped, the same metric space properties obtain as before: $p(i, j) \geq 0$ (non-negativity), $p(i, j)=p(j, i)$ (symmetry), $p(i, i)=1$ (reflexivity), and $p(i, j) \geq p(i, k)+p(k, i)-1$ (triangular inequality).
} 
$\mathbf{c}_{1}(i, k)=\mathbf{c}_{2}(i, k)$ are true for some $i, j, k \in\{1, \ldots, n\}$.

Cases of perfect conflict and agreement, although rare, are fairly straightforward. In the former, the graphs constructed from $\mathbf{C}_{1}$ and $\mathbf{C}_{2}$ are complements of each other, as in the case of countries with and without shared borders, or allied and non-allied relationships. In the latter, the graphs are isomorphic, and one might be justified in assuming that the specifications 1 and 2 represent the same theoretical concept. In each case, $\mathbf{C}_{1}$ and $\mathbf{C}_{2}$ are highly dependent on one another; knowing whether a connection exists between $i$ and $j$ in $\mathbf{C}_{1}$ allows us to perfectly predict whether the same pairwise tie exists in $\mathbf{C}_{2}$. The key difference lies in the interpretation of spatial dependence. If two graphs are in perfect conflict, positive spatial autocorrelation detected in one graph appears as negative autocorrelation in the other - diffusion becomes repellence, clustering becomes segregation.

Partial conflict or agreement are more ambiguous cases. Here, matrices $\mathbf{C}_{1}$ and $\mathbf{C}_{2}$ partially overlap and represent potentially related networks, though not necessarily ideal substitutes. The structural similarity between the graphs can vary from very high - approaching that of perfect conflict or agreement - to negligible - where the graphs represent connections in unrelated types of networks. In IR, most interstructural relationships reside in this murky domain. Border contiguity may or may not correlate with inter-capital distance, labor migration may or may not correlate with bilateral trade, and so on. Due to the variety of ways in which connectivities can be specified, even networks situated in different types topological space may be more structurally similar than those, which share the same space and distance metrics.

\section{Finding the "True" Network: A Monte Carlo Study}

What are the consequences of the CNP for empirical research? As we demonstrate below using Monte Carlo simulation, network misspecification can result in biased spatial autocorrelation estimates, poor model fit and inaccurate predictive performance. Use of a specification in partial conflict or agreement with the true graph significantly increases the risk of Type II errors: a genuine process of diffusion is left undetected. Use of a specification in perfect conflict all but guarantees a Type "S" error (Gelman and Tuerlinckx, 2000): a genuine process of diffusion is mistaken for a process of repellence. ${ }^{8}$ We propose a three-step method to approach the network specification process and arbitrate between multiple candidates in a systematic way.

In modeling the process of diffusion, the binary graph $\mathbf{C}_{m}$ is typically transformed by row standardization or some measure of decay into a spatial weight matrix $\mathbf{W}_{m}$, which governs how neighbors influence each other (e.g. competitively, cumulatively, in inverse proportion to distance). The cross-product of $\mathbf{W}_{m}$ and the dependent variable vector $\mathbf{y}$ is the spatial lag $\mathbf{W}_{m} \mathbf{y}$, which can be interpreted as a weighted sum or average of neighboring values of $\mathbf{y}$. In the simple case of cross-sectional data with a normally-distributed dependent variable, we can model the diffusion

\footnotetext{
${ }^{8}$ Gelman and Tuerlinckx $(2000,2)$ define Type "S" (for sign) errors as falsely "claiming that $\theta_{1}>\theta_{2}$ when in fact $\theta_{2}>\theta_{1} . "$
} 
process with a Spatial Autoregressive (SAR) model:

$$
\begin{aligned}
\mathbf{y} & =\rho_{m} \mathbf{W}_{m} \mathbf{y}+\mathbf{X} \beta+\epsilon \\
& =\left(\mathbf{I}-\rho_{m} \mathbf{W}_{m}\right)^{-1} \mathbf{X} \beta+\left(\mathbf{I}-\rho_{m} \mathbf{W}_{m}\right)^{-1} \epsilon \\
\epsilon & =N(0,1)
\end{aligned}
$$

which resembles an Ordinary Least Squares (OLS) regression with the addition of the lagged term and the spatial autocorrelation coefficient $\rho_{m} \cdot{ }^{9}$ Although many IR applications, including the one considered below, call for more complex models to accommodate longitudinal data and categorical dependent variables, the basic intuition is the same. The outcome $\mathbf{y}$ is modeled as a function of the linear predictor on the right side of the equation, which includes outcomes in neighboring units $\mathbf{W}_{m} \mathbf{y}$, a set of exogenous covariates $\mathbf{X}$ and an independent error term $\epsilon$.

An underlying assumption of the SAR model is that the matrix $\mathbf{W}_{m}$ captures the one "true" network of diffusion, through which the observed data were generated. In most empirical research, however, this "true" connective structure is almost always unobserved. Misspecification of this structure has been shown to generate inconsistent parameter estimates and misleading conclusions (Anselin, 2002; Fingleton, 2003; Lee, 2009).

Suppose, however, that we have two or more competing proximity measures $m=1,2$ (say, border contiguity and some critical level of bilateral trade). We would like to know which of these is closer to the "truth," so as to include it in the SAR model. The conventional approach of spatial econometrics has been to treat network specification as a variable or model selection problem:

1. Strength of autocorrelation $\left(\rho_{m}\right)$. One fits a model for each matrix $\left(\mathbf{W}_{1}, \mathbf{W}_{2}\right)$, examines whether the respective autocorrelation coefficients $\left(\rho_{1}, \rho_{2}\right)$ are statistically different from what we would expect by chance, and selects the model where the strength and significance of the spatial dependence is greatest. This procedure has a long history in theoretical and applied work on spatial econometrics. Kooijman (1976) proposed matrix selection by maximization of the Moran's I autocorrelation coefficient, while O'Loughlin and Anselin (1991, 42-44) selected among multiple connectivity matrices by examining the relative size and significance of a general cross-product measure of spatial association.

2. Goodness-of-fit diagnostics for non-nested models. One selects a model that minimizes a statistic, like Akaike Information Criterion (AIC) or Bayesian Information Criterion (BIC), which balances an analysis of deviance with a penalty for model complexity. Although

${ }^{9}$ Estimation can be accomplished with maximum likelihood. The SAR model has a full log-likelihood of the form

$$
\begin{aligned}
\ln L & =-\frac{n}{2} \ln \left(\pi \sigma^{2}\right)+\ln \left|\mathbf{I}-\rho_{m} \mathbf{W}_{m}\right|-\frac{\epsilon^{\prime} \epsilon}{2 \sigma^{2}} \\
\epsilon & =\left(\mathbf{I}-\rho_{m} \mathbf{W}_{m}\right)^{-1} \mathbf{y}-\mathbf{X} \beta
\end{aligned}
$$


log-likelihood and similar diagnostics are general model selection tools, spatial econometricians have also recommended their use as criteria for the selection of spatial weight matrices (Anselin, 2002; Lee, 2009).

3. Cross-validation. Each model is estimated - repeatedly - on a random subset of data, and its predictive performance is evaluated on previously unseen out-of-sample data. This procedure is a popular check against overfitting in a wide class of models (Ward et al., 2010), and is occassionally applied to the selection of connectivity criteria in spatial econometrics (Ertur et al., 2007).

Beyond these three, a range of other procedures has been proposed by spatial econometricians, such as estimating spatial weights matrices based on an observed pattern of spatial dependence (Bhattacharjee and Jensen-Butler, 2005), Bayesian model comparison (Holloway and Lapar, 2007), Bayesian model averaging (LeSage and Parent, 2007) and component-wise boosting algorithms (Kostov, 2010). Because most of these procedures are restricted to highly specialized classes of spatial models, we limit our attention to the three more general selection approaches listed here.

To assess the relative performance of these procedures in addressing the CNP, we performed a series of Monte Carlo experiments in which models were estimated using 1,000 random graphs, each with a different degree of structural similarity to the one "true" network of diffusion. The true network ( $\mathbf{C}$, row normalized as $\mathbf{W}$ ) was assumed to be the most commonly-used measure in international relations: border contiguity. The data generating process was based on the SAR model as defined in (2): the $\mathbf{X}$ matrix included an intercept term and a normally-distributed random variable, the $\beta$ vector consisted of the arbitrary coefficients [.01 4$]$, and the true autoregressive parameter $\rho$ was evaluated at an arbitrary value of .1, indicating weak positive autocorrelation.

Based on our knowledge of the "true" network, we generated 1,000 random graphs with varying degrees of structural similarity to $\mathbf{W}$. To determine the degree of conflict or agreement between the competing proximity measures, we relied on an edge-set comparison diagnostic called graph correlation (Krackhardt, 1987, 1988; Butts and Carley, 2001, 2005). ${ }^{10}$ Each full set of connectivities (the matrix $\mathbf{C}_{m}$ ) was treated as a random variable, given that each matrix was built on the same set of objects (countries), and that the dimensions and ordering of rows and columns were identical. ${ }^{11}$ For each $\mathbf{C}_{m}$, we began by calculating the graph mean, $\mu_{m}$, understood as the expectation of a uniform draw from the matrix. For the binary connectivity matrices considered here, $\mu_{m}$ could be interpreted as the graph's density, or proportion of existing connections relative to the total number possible, $n(n-1) / 2$. With this information, we calculated the covariance between two graphs $\mathbf{C}_{1}$

\footnotetext{
${ }^{10}$ While alternative techniques have been proposed for this purpose - e.g. graph-level indices, algebraic and model-based methods - a direct comparison of the full sets of pairwise connections, or edges, enables us to evaluate correspondence between structures more efficiently and with no parametric assumptions.

${ }^{11}$ For the more complicated case where permutations are allowed, see Butts and Carley (2001).
} 
and $\mathbf{C}_{2}$ :

$$
g \operatorname{cov}\left(\mathbf{C}_{1}, \mathbf{C}_{2}\right)=\frac{1}{n(n-1)} \sum_{i=1}^{n} \sum_{j=1}^{n-1}\left(\mathbf{c}_{1}(i, j)-\mu_{1}\right)\left(\mathbf{c}_{2}(i, j)-\mu_{2}\right)
$$

and the variance of each graph, which is simply the covariance of the graph with itself:

$$
\operatorname{gvar}\left(\mathbf{C}_{1}\right)=\frac{1}{n(n-1)} \sum_{i=1}^{n} \sum_{j=1}^{n-1}\left(\mathbf{c}_{1}(i, j)-\mu_{1}\right)^{2}
$$

The graph correlation coefficient gcor could then be computed as:

$$
\operatorname{gcor}\left(\mathbf{C}_{1}, \mathbf{C}_{2}\right)=\frac{g \operatorname{cov}\left(\mathbf{C}_{1}, \mathbf{C}_{2}\right)}{\sqrt{\operatorname{gvar}\left(\mathbf{C}_{1}\right) \operatorname{gvar}\left(\mathbf{C}_{2}\right)}}
$$

Graph correlation has an interpretation analogous to the common Pearson product-moment correlation coefficient. In the context of the Conflicting Neighbor Problem, a value of -1 indicates that two graphs are in perfect conflict, a value of +1 indicates that they are in perfect agreement. Values between these extremes indicate partial conflict $(-1,0)$ or partial agreement $(0,1)$.

For each of the $m \in\{1, \ldots, 1000\}$ random graphs $\mathbf{C}_{m}$, with $\operatorname{gcor}\left(\mathbf{C}, \mathbf{C}_{m}\right) \in(-1 ; 1)$, we rownormalized the matrix to create $\mathbf{W}_{m}$, fit the model in (1) using maximum likelihood, and recorded the autocorrelation parameter estimate $\left(\hat{\rho}_{m}\right)$, its standard error $\left(S E\left[\hat{\rho}_{m}\right]\right)$, and the model's AIC and BIC statistics. We also performed repeated random sub-sampling cross-validation, and reported the mean RMSE and 95\% confidence interval for each of the 1,000 graphs. ${ }^{12}$

The results of the Monte Carlo study are shown in Figure 1. The horizontal axis in each plot displays the graph correlation of each $\mathbf{C}_{m}$ with the true matrix $\mathbf{C}$. The vertical axes report statistics corresponding to the three model selection criteria of statistical significance, goodness-of-fit and cross-validation: [1a] spatial autocorrelation parameter estimates (points) and 95\% confidence intervals (grey lines), relative to 0 (dashed line) and the true value (red line), [1b] AIC statistics (points), and [1c] out-of-sample RMSE means (points) and 95\% confidence intervals (grey lines).

1. Strength of autocorrelation. As shown in Figure 1a, the autocorrelation estimate $\hat{\rho}$ converges to the true value $(\rho=.1)$ as gcor approaches 1 . If one were to select a model based exclusively on the the size and significance of the coefficient, however, a graph in perfect conflict $($ gcor $=-1)$ would be as likely a choice as one in perfect agreement $($ gcor $=1)$.

\footnotetext{
${ }^{12}$ For each of the 1,000 graphs, we calculated the spatially lagged dependent variable using $\mathbf{W}_{m}$, randomly selected $90 \%$ of the data into a training set and $10 \%$ into a validation set, and ran a SAR model on the training data. We then used the model's parameters to calculate predicted values for the validation set and recorded the root mean squared error (RMSE) for these out-of-sample predictions. We repeated this procedure with 100 random partitions of the data and averaged RMSE statistics over these 100 runs.
} 
Due to an inability to distinguish between conflict and agreement, the significance criterion does little to avert the risk of mistaking diffusion for repellence - a Type "S" error, in the terminology of Gelman and Tuerlinckx (2000). If the candidate network is misspecified such that it has only negligible overlap with the true graph (gcor is close to 0), confidence intervals cover the origin and Type II errors become likely.

2. Goodness-of-fit. As shown in Figure 1b, information criteria like AIC and BIC do a far better job of adjudicating between graphs positively and negatively correlated with the true network. ${ }^{13}$ However, this advantage is most profound only in cases of near-perfect agreement, where gcor $>$.8. Elsewhere, as in cases of partial and perfect conflict, the relationship between graph correlation and AIC is concave. While a graph with gcor $=.6$ is more likely to be selected than one with $g c o r=.4$, so too would a graph with $g c o r=-.6$, even though the $g c o r=.4$ graph is in fact closer to the "truth".

3. Cross-validation. As shown in Figure 1c, out-of-sample prediction diagnostics also exhibit a concave relationship with graph correlation. Like AIC, RMSE performs quite well for graphs in near-perfect agreement with the true network: a graph with $g$ cor $=.99$ predicts outcomes in out-of-sample data with considerably greater accuracy than a graph with $g c o r=-.99$. For most graphs in the middle, however, higher prediction accuracy is an indication of the scale of correlation with the true network, not the direction of that correlation.

Assuming that researchers have an interest in the substantive meaning of spatial dependence, in addition to its mere presence or absence, there is a point at which the utility of model fit diagnostics ends and the importance of theory begins. The ambiguity of the three diagnostics lies in the fact that - outside of extreme cases - none of them can effectively eliminate the risk of Type "S" error. Since diffusion implies positive spatial autocorrelation, however, we can potentially impose a strong prior on the sign of $\rho_{m}$, restricting our search to the sections of Figure 1 where gcor $\geq 0$. Since model fit and cross-validation statistics are monotonic in this region, the model selection exercise would be vastly simplified.

\section{A Three-Step Procedure}

We propose a simple procedure to choose among multiple sets of neighbors:

First step: Network specification. Define the set of plausible networks for a given set of units. For each network, define (1) the space the objects occupy, (2) the measure of distance between them and (3) the connectivity criterion used to distinguish between neighbors and non-neighbors.

\footnotetext{
${ }^{13}$ Because the number of parameters was the same across the 1,000 models, AIC and BIC results were almost identical. For this reason, only the former are reported in Figure 1.
} 
Second step: Diagnostics. Examine pairwise correlations between the graphs. If any of the correlations are negative, use a theoretically-informed prior about the direction of spatial dependence to reduce the set of graphs to only those positively correlated with each other. Estimate the model with each graph. Use a combination of parameter-level (significance) and model-level diagnostics (goodness-of-fit, cross-validation) to eliminate candidate graphs that bear little or no structural resemblance to the true, unobserved network. These include graphs that produce insignificant autocorrelation parameters, and models with relatively high deviance statistics and poor predictive performance.

Third step: Simulation. If more than one graph survives the second step, use simulation to illustrate the empirical implications of the best-performing theories. This involves the disaggregation of diffusion effects into specific counterfactual predictions of the sort: "If a change occurs in unit $i$, how will it influence some outcome in unit $j$ given network structure $m$ ?"

Each of the three steps is guided by theoretical considerations - about the universe of graphs to be considered, about the direction of dependence and the specification of the diffusion model itself, about the counterfactual scenario to be simulated. This procedure is illustrated below for a famous empirical example from international relations: the spread of democracy. The Conflicting Neighbor Problem here lies in the uncertainty of the network through which political regime change can spread, and the structural overlap between candidate networks, which include several common geographic and non-geographic measures of proximity.

\section{Application: The Spread of Democracy}

In "Diffusion and the International Context of Democratization," Kristian Gleditsch and Michael Ward argue that international factors can exert a strong influence on the prospects and durability of transitions to democracy (Gleditsch and Ward, 2006). Pointing to patterns of geographic clustering in the global distribution of democratic regimes and transitions to democracy, the authors argue that democratic regimes are more likely to emerge and endure in regions with a high proportion of neighboring democratic states, and that regime transitions tend to impart a regional convergence. ${ }^{14}$

The magnitude of democratic "spillover effects", however, may be highly dependent on one's choice of network. Specifically, what signal needs to be transmitted for the diffusion of democracy to take place, and what are the pathways through which the signal is likely to travel? The authors write, "one can think of diffusion in terms of how linkages to external actors and events influence the relative power and the likely strategies and choices of relevant groups in struggles over political institutions and outcomes" (Gleditsch and Ward, 2006, 918). By this statement, the signal that must be transmitted appears to be information - about the utility of various political institutions,

\footnotetext{
${ }^{14}$ Background on the Gleditsch and Ward (2006) model is provided in the Appendix.
} 
about the costs, benefits or perceived probability of regime change, about successful or failed strategies for political reform. The authors capture this process with a network of geographically contiguous states. As we demonstrate below, however, these signals can conceivably be transmitted through a number of different pathways.

\section{Step 1: Enumeration of Network Specifications}

As a first step in our reanalysis, we begin by specifying the set of networks to be considered as potential pathways of diffusion. Because categories of international networks are quite broad and encompass a wide variety of possibilities, we limit our survey to six distance metrics defined on geographic and nongeographic space: [1] interborder distance, [2] intercapital distance, [3] ethnic ties, [4] bilateral trade, [5] intergovernmental organizations, and [6] military alliances. An overview of their formal definitions and substantive assumptions is provided below.

1. Interborder distance (geographic space). Let $\mathbf{B}_{i}$ be the set of boundary points on polygon $i$ (i.e. the political borders of a country), and let $b_{i}$ be an element of $\mathbf{B}_{i}$ (i.e. the coordinates of a single boundary point). Similarly for $\mathbf{B}_{j}$. The interborder distance between $i$ and $j$ is defined as the minimum distance between all pairs of boundary points on each polygon:

$$
d(i, j)=\min _{b_{i} \in \mathbf{B}_{i}, b_{j} \in \mathbf{B}_{i}} d\left(b_{i}, b_{j}\right)
$$

Assuming that a signal can be transmitted by cross-border movements of people and goods, a shorter distance between the political borders of two countries is expected to reduce the costs of transmission. This is the metric used by Gleditsch and Ward (2006) in their original analysis.

2. Intercapital distance (geographic space). Let $\left(x_{i}, y_{i}\right)$ be the Cartesian coordinates of the capital city of country $i$. Similarly for $\left(x_{j}, y_{j}\right)$. The intercapital distance between $i$ and $j$ is defined as the Euclidean distance between these points:

$$
d(i, j)=\sqrt{\left(x_{j}-x_{i}\right)^{2}+\left(y_{j}-y_{i}\right)^{2}}
$$

Assuming that a signal can be transmitted by official travel and political communication, a shorter distance between the political capitals of two countries is expected to reduce the costs of transmission (Lee and Strang, 2006; Bach and Newman, 2010).

3. Ethnic proximity (nongeographic space). Let $E_{i}$ be the set of unique ethnolinguistic groups residing within the borders of country $i$. Similarly for $E_{j}$. The ethnic proximity between $i$ 
and $j$ is defined as the number of shared groups that reside within both countries:

$$
p(i, j)=\left|E_{i} \cap E_{j}\right|
$$

If two countries are home to related ethnic or linguistic groups, these ethnic and cultural ties can facilitate the flow of information through common media markets, interpersonal contacts, or cognitive shortcuts on the appropriateness of a particular political system given a set of shared values (Simmons and Elkins, 2004).

4. Trade proximity (nongeographic space). Let $\tau(i, j)$ be the volume of exports from country $i$ to country $j$ and let $\tau(j, i)$ be the volume of imports to $i$ from $j$. The trade proximity between $i$ and $j$ is defined as the sum of these two quantities:

$$
p(i, j)=\tau(i, j)+\tau(j, i)
$$

If two countries are major trading partners, information may flow through the exchange of consumer goods or through interpersonal contacts among business elites (Greenhill et al., 2009). Additionally, trade relations may make countries more responsive to human rights concerns, labor standards and other norms of behavior, particularly if such expectations are backed by the possibility of positive or negative trade sanctions.

5. Intergovernmental proximity (nongeographic space). Let $I_{i}$ be the set of intergovernmental organizations (IGOs) in which country $i$ formally participates. Similarly for $I_{j}$. The intergovernmental proximity between $i$ and $j$ is defined as the number of IGOs in which the two countries jointly participate:

$$
p(i, j)=\left|I_{i} \cap I_{j}\right|
$$

If two countries are members of the same intergovernmental organizations (IGOs), regularized contacts between political, government or military elites may provide opportunities for international socialization, where states observe and mimic the actions of others, defining and internalizing the norms of behavior condoned by the larger group (Cao, 2009; Greenhill, 2010).

6. Alliance proximity (nongeographic space). Let $A_{i}$ be the set of collective or mutual defense treaties of which country $i$ is a signatory. Similarly for $A_{j}$. The alliance proximity between $i$ and $j$ is defined as the number of alliances involving both countries:

$$
p(i, j)=\left|A_{i} \cap A_{j}\right|
$$

Like IGOs, alliances provide a forum for elite socialization - through common military stan- 
dards, training, doctrines, weapons systems and missions (Hammarstrom and Heldt, 2002). Unlike many IGOs, alliances are typically smaller, more exclusive communities, with more robust means to monitor compliance and punish those who deviate, as evidenced by the Warsaw Pact's interventions to prevent democratic liberalization in Hungary in 1956 and Czechoslovakia in 1968.

One reason for the popularity of geographical distances in IR research is the assumption that exogeneity is automatically ensured: the physical locations of cities and borders are relatively static and often causally prior to the diffusion process under consideration (Kostov, 2010). The same cannot always be said of nongeographic space. The endogeneity of international regimes and institutions has been the focus of a vast body of research (Keohane, 1988; Simmons and Martin, 2001), as have problems of homophily and endogeneity in network formation more broadly (McPherson et al., 2001; Shalizi and Thomas, 2011). Although great care should always be taken in drawing causal inferences from models based on nongeographic measures of distance and proximity - and an adequate treatment of their identification lies outside the scope of our paper - there are equally compelling reasons to include these metrics in our survey.

First, the two types of space often overlap. Intergovernmental organizations and alliances are often regional in focus; trade is less costly when conducted between geographic neighbors; ethnic groups cluster geographically. While justifications for network specifications are rarely explicit, the prominence of border contiguity in IR is unlikely due to the plausibility of the assumption that politically-relevant information can only be transmitted by cross-border movements. Intentionally or not, our interpretation of geographical space is already imbued with political meaning. If we insist on maintaining a conceptual separation between geographic and nongeographic space, the structural distinctions between these two classes of networks should be measured rather than assumed.

Second, the current direction of diffusion research dictates that model comparisons be carried out across, rather than just within particular types of topological space. While some studies are more careful about identification challenges than others, scholars are increasingly moving past geography to indicators of actual political, cultural and economic communication (Beck et al., 2006; Hafner-Burton et al., 2009; Greenhill et al., 2009; Cao, 2010; Greenhill, 2010). The increasing attention on nongeographic space stems from its relatively direct theoretical appeal. Such relationships are substantively easier to relate to some of the mechanisms associated with certain types of diffusion: if we are interested in modeling the adoption of common military technology and doctrine, joint membership in a military alliance may seem a more suitable choice than shared borders. A systematic examination of other types of space is an effort to let theory to drive our measurement choices and not the other way around.

The challenge that remains is one of comparability: each metric is distributed and scaled in a different way, making direct comparisons difficult. While some relationships, like border contigu- 
ity and military alliances, are directly translatable into connectivities, others are continuous (e.g. capital-to-capital distance, trade flows) or cumulative (e.g. number of shared ethnic groups, or the number of intergovernmental organizations in which two countries jointly participate). In the latter case, pairwise connections are not immediately apparent from the raw data. After all, how much bilateral trade makes two states "significant trade partners"? Connectivity criteria provide a consistent way to relate these metrics to discrete definitions of "neighborhood", provided that the resulting binary graphs reflect a quantity of theoretical interest and approximate the geometry of the continuous case. ${ }^{15}$ We consider four connectivity criteria below:

1. Thresholding. Let $r$ be a search radius defined on space $S$. Countries $i$ and $j$ are considered neighbors if they are located within $r$ spatial units of each other.

$$
\begin{aligned}
\mathbf{c}_{\text {THRES }}(i, j) & =1\{i, j \in S: d(i, j) \leq r\} & & \text { (distance) } \\
& =1\{i, j \in S: p(i, j) \geq r\} & & \text { (proximity) }
\end{aligned}
$$

The simplest connectivity criterion imposes some theoretically meaningful threshold value on the distance or proximity metric under consideration. The advantage of thresholding lies in its simplicity and interpretability. The disadvantage is that the choice of $r$ is at once arbitrary and highly consequential, particularly where the distribution of objects in space is not uniform: a $500 \mathrm{~km}$ threshold on interborder distance - the criterion used by Gleditsch and Ward (2006) - means a quite different thing in Oceania than in Central Europe. An overly conservative radius can create a high proportion of neighborless isolates, while an overly expansive one can create a high number of politically irrelevant connections. This trade-off entails a host of theoretical and computational concerns (Bivand et al., 2008).

2. Minimum distance. Let $r=\max _{i=1}^{n} \min _{j \neq i}^{n-1} d(i, j)$ be the maximum first nearest neighbor distance between all pairs of objects in space $S$. Countries $i$ and $j$ are considered neighbors if they are located within $r$ spatial units of each other.

$$
\begin{array}{rlrl}
\mathbf{c}_{M D N}(i, j) & =1\left\{i, j \in S: d(i, j) \leq \max _{i=1}^{n} \min _{i \neq j}^{n-1} d(i, j)\right\} & & \text { (distance) } \\
& =1\left\{i, j \in S: p(i, j) \geq \min _{i=1}^{n} \max _{i \neq j}^{n-1} p(i, j)\right\} & \text { (proximity) }
\end{array}
$$

\footnotetext{
${ }^{15} \mathrm{~A}$ number of conventions have been proposed for optimal threshold selection for valued ties, including rank discrepancy minimization and simulation (Thomas and Blitzstein, 2009b). Since any dichotomization can result in a considerable loss of information, the alternative might be to avoid thresholding altogether, treat all nonzero pairs as neighbors, and settle on a continuous measure of connectivity like inverse network distance, frequency or bandwidth. Due to the high density of resulting matrices, this approach might itself entail some of computational and theoretical problems. For our purposes, dichotomization also offers the benefits of consistency and simplicity in measurement, modeling, inference and prediction.
} 
An extreme solution to the "island" problem is the use of minimum distance connectivities, a special case of thresholding that ensures that the most isolated object in the system will have at least one neighbor and the rest will have as many neighbors as can be found within the corresponding search radius. The advantage of minimum distance is that it eliminates the neighborless unit problem encountered with arbitrary threshold specifications. However, it is highly inefficient for irregularlyspaced units - of which countries in the international system are an example. In regions with a high density of units, such as Central Europe and much of West Africa, an excessive number of connections results in a high noise-to-signal ratio.

3. $k$-nearest neighbor. Let $d_{(1)}(i,-) \leq \cdots \leq d_{(n)}(i,-)$ be the order statistics for the distances between point $i$ and all other points in the set $\{1, \ldots, n\}$, and let $p_{(1)}(i,-) \geq \cdots \geq p_{(n)}(i,-)$ be the order statistics for the proximities. Countries $i$ and $j$ are considered neighbors if $j$ is one of the $k$ nearest neighbors of $i$.

$$
\begin{aligned}
\mathbf{c}_{K N N}(i, j) & =1\left\{i, j \in S: d(i, j) \leq d_{(k)}(i,-)\right\} & & \text { (distance) } \\
& =1\left\{i, j \in S: p(i, j) \geq p_{(k)}(i,-)\right\} & & \text { (proximity) }
\end{aligned}
$$

Another variety of threshold-based criteria, the $k$-nearest neighbor criterion takes into account differences in the densities of areal units, ensuring that all observations have the same number of incoming ties, while avoiding much of the noise associated with minimum distance measures. One drawback is that $k$ nearest neighbor methods produce a potentially high number of asymmetric connectivities (country $i$ is a neighbor of country $j$ but not vice-versa), which may or may not be problematic, depending on the nature of the phenomenon under study. More crucially, the selection of $k$ may not reflect the "true" level of a unit's isolation or connectedness, since the number of neighbors is uniform across the system. ${ }^{16}$

3. Sphere of Influence. Let $O_{i}$ be a circle centered at point $i$, with radius $r_{i}=\min d(i,-)$, that point's first nearest neighbor distance. Let $O_{i} \cap O_{j}$ be the intersection between circles $O_{i}$ and $O_{j}$. Objects $i$ and $j$ could thus be considered sphere of influence neighbors whenever $O_{i}$ and $O_{j}$ intersect in exactly two points (Avis and Horton, 1985, 323):

$$
\mathbf{c}_{S O I}(i, j)=1\left\{i, j \in S: O_{i} \cap O_{j} \neq \emptyset\right\} \quad \text { (Cartesian coordinate system) }
$$

As illustrated in Figure 2, the sphere of influence graph requires information on the relative placement of nodes on a geographic or planar coordinate system. For a more general case, we may reach a naive approximation with a pseudo sphere of influence criterion, which relies on

\footnotetext{
${ }^{16}$ This setup is similar to the "name $k$ friends" procedure in social network data collection, which truncates the sample space of the family of networks and has been shown to introduce bias into the estimation of autocorrelation and network effects (Thomas and Blitzstein, 2009a).
} 
the symmetrization of a $k=1$ nearest neighbor matrix. Two countries $i$ and $j$ are considered neighbors if either $j$ is the first nearest neighbor of $i$ or vice versa:

$$
\begin{aligned}
\mathbf{c}_{p S O I}(i, j) & =1\left\{i, j \in S: d(i, j)=d_{(1)}(i,-) \cup d(j, i)=d_{(1)}(j,-)\right\} & & \text { (general distance) } \\
& =1\left\{i, j \in S: p(i, j)=p_{(1)}(i,-) \cup p(j, i)=p_{(1)}(j,-)\right\} & & \text { (general proximity) }
\end{aligned}
$$

Like $k$ nearest neighbor, the sphere of influence graph ensures that all units have at least one neighbor and produces a far sparser matrix than the more noisy minimum distance specification. This approach is well-suited for irregularly-located areal entities: the method does not require a user-defined parameter like $r$ or $k$, the number of connections per unit is variable and relatively long links are avoided. The disadvantage is that inferences made from sphere of influence neighbors are not as immediately intuitive as in the first three approaches. In international relations, (pseudo) sphere of influence neighbors tend to assume relatively few connections per country.

\section{Step 2: Structural Comparisons and Model Diagnostics}

Once the list of candidate graphs is enumerated, we may proceed to construct connectivity matrices based on real data, and assess the degree of overlap between the specifications. To facilitate the estimation of geographic networks for all country years between 1875 and 1998, we created a separate ESRI shapefile (polygon-based digital map) for each year of observation, to account for the numerous boundary changes, partitions and unifications that have taken place over the course of the period of observation. ${ }^{17}$ To facilitate estimation of the non-geographic networks for each year, we constructed graphs from several dyadic panel datasets, including the Correlates of War Dyadic Trade, (Barbieri and Pollins, 2009), Intergovernmental Organization (Pevehouse and Warnke, 2004) and Alliance (Gibler and Sarkees, 2004) datasets. To construct the ethnic network, we joined our historical state borders data with the Geo-Referencing of Ethnic Groups (Weidmann et al., 2010) polygons, and computed the number of shared ethnic groups residing within the borders of each pair of countries. ${ }^{18}$

Figure 3 shows the full set of graphs derived from these specifications. Simple thresholding was used for two metrics. For interborder distance, we kept Gleditsch and Ward (2006)'s value of $500 \mathrm{~km}$ as the distance separating the nearest border points of neighboring countries:

\footnotetext{
${ }^{17}$ For a summary of the major changes, see Gleditsch and Ward (2001, 16-17). Since the earlier years in the dataset contain many fewer cross-sectional observations than more recent years, dependencies and other non-self governing entities were treated as missing data prior to the year of their independence. The resulting shapefiles were then joined with Gleditsch and Ward (2006) data, and were used as base maps for the estimation of unique weights matrices for each calendar year. Weidmann et al. (2010) have recently made available the excellent CShapes historical boundary data available in $\mathrm{R}$ and ESRI formats.

${ }^{18}$ Unlike the Correlates of War data, which is measured at the level of dyad-year, the GREG ethnicity dataset is based on ethnic boundaries from a single cross-section from the widely-used Soviet Atlas Narodov Mira (1964). While the ethnic network is nonetheless dynamic, all variation across time is due to changes of state borders, rather than changes in settlement patterns - the latter of which are assumed constant (Weidmann et al., 2010).
} 
$\mathbf{c}_{C O N T}(i, j)=1\left\{i, j \in S: \min d\left(b_{i}, b_{j}\right)<500\right\}$. For alliance proximity, we assumed that the existence of even one mutual defense pact was a sufficient threshold to classify two countries as allies: $\mathbf{c}_{A L L Y}(i, j)=1\left\{i, j \in S:\left|A_{i} \cap A_{j}\right|>0\right\}$. For all other metrics, we applied the criteria of minimum distance, $k=4$ nearest neighbors, and sphere of influence. The densest graphs were produced by the minimum distance criterion, designed to ensure that each country has at least one neighbor. The sparsest graphs were produced by sphere of influence, which restricted the search only to the immediate vicinity of each country. $k=4$ nearest neighbors produced some quite asymmetrical connectivities: while each country had at least four neighbors (incoming ties), there were no restrictions on how many times a country could be a neighbor to others (outgoing ties).

What is the degree of structural similarity between these measures? Figure 4 shows a graph correlation matrix for the fourteen graphs defined above. ${ }^{19}$ Almost all graphs are in partial agreement with each other. The strongest positive correlations are those between - and within - geographic and ethnic ties. Gleditsch and Ward (2006)'s original measure of border contiguity is strongly correlated with the $k=4$ nearest neighbor specification of intercapital distance and minimum distance ethnic neighbors $($ gcor $>6)$. Trade, meanwhile, is only weakly correlated with other specifications, suggesting that patterns of international commerce are not constrained by the limits of geographic and ethnic proximity. Intergovernmental and alliance ties exhibit low-to-moderate overlap with geographic and ethnic ties and little overlap with trade. Only one graph - IGO $O_{M N}$ - is in partial conflict (negatively correlated) with any other, a likely artifact of the density of the matrix as shown on Figure 3. Due to this conflict, we would expect the graph to yield different autocorrelation estimates from the alternatives - perhaps estimating repellence where the other graphs estimate diffusion.

Once the new sets of connectivity matrices were created, we adopted the same spatial weights (competitive and cumulative) to re-code the two spatial variables used in Gleditsch and Ward (2006): proportion of neighboring democracies and neighboring transitions to democracy, as defined in the Appendix. The yearly cross-sections were then remerged into a full dataset, spanning 1875-1998. ${ }^{20}$ To contrast the authors' original findings with those produced by alternative definitions of the "local context," we reanalyzed their models with the fourteen connectivity specifications shown in Figure 3.

To find the most plausible graph (and model) given the observed data and theory specified by Gleditsch and Ward (2006), we begin by separating promising candidate graphs from those that bear little or no structural resemblance to the true, unobserved network. Figure 5 shows a series of parameter-level and model-level diagnostics that serve this purpose. These diagnostics suggest that

\footnotetext{
${ }^{19}$ Although geographic and network data for all years (1875-1998) were used in the models, only 1998 data are shown in Figure 4.

${ }^{20}$ While the contiguity measure is exactly the same as the one used by Gleditsch and Ward (2006) the results differ due to a typo in the specification of the original model. The result is that neighboring transition to democracy is allowed to enter the model when the country is either a democracy or an autocracy in the previous period. The results presented here reflect the corrected model.
} 
the spatial structure implied by connectivity assumptions can profoundly change inferences about the process of diffusion. While ethnicity and trade are weak, even negligible, carries of democracy, alliances and international institutions can provide pathways at least as compelling as geography.

To evaluate the strength and significance of the diffusion process itself, we asked the following counterfactual question: would a median autocratic state be more likely to democratize if its neighbors were more democratic? For each model, we simulated the effect of a one standard-deviation increase in the proportion of neighboring democratic states on the relevant transition probability, autocracy to democracy $(A \rightarrow D)$. As shown in Figure 5a, the magnitude, direction and estimation certainty of the neighborhood effect vary considerably by connectivity type. Although - in most cases - a more democratic neighborhood is associated with a higher probability of democratic regime change, this effect is significantly different from zero under just three of the measures: intercapital distance $\left(G E O_{K N N 4}\right)$, intergovernmental organizations $\left(I G O_{K N N 4}\right)$ and alliance ties (Alliance). With all other networks, including the one originally specified by the authors $\left(G E O_{C O N T}\right)$, the effect is positive but insignificant. Only for $I G O_{M D N}$ - the graph in partial conflict with other candidates in Figure 4 - is the effect negative, though insignificant.

Figure 5b reports model-level goodness-of-fit statistics (AIC) for all measures. Although the number of parameters is the same across the fourteen models and none can be penalized for its relative complexity, deviance statistics indeed vary across the different specifications. Not surprisingly, the best-performing models are ones in which the estimated diffusion effect is strongest: intercapital distance $\left(G E O_{K N N 4}\right)$, intergovernmental organizations $\left(I G O_{K N N 4}\right)$ and alliance ties (Alliance).

The same pattern holds when the models are subjected to cross validation tests. Following Ward et al. (2010), we repeated the following procedure 100 times for each of the fourteen measures: randomly partition the data into a training set $(90 \%)$ and validation set (10\%), estimate Model 3 from Gleditsch and Ward (2006) on the training set, evaluate out-of-sample prediction accuracy by calculating the area under the receiver-operator curve (AUC) on the validation data. The average out-of-sample AUC and 95\% confidence intervals for the 100 runs of each model are reported in Figure 5c. Prediction accuracy is highest $(A U C>.99$, with narrow confidence intervals) for alliance ties and intergovernmental organizations, followed by intercapital distance.

These diagnostics consistently point to the same decision: we can safely eliminate all candidate graphs, save intercapital distance $\left(G E O_{K N N 4}\right)$, intergovernmental organizations $\left(I G O_{K N N 4}\right)$ and alliance ties (Alliance). Of the three finalists, military alliance networks offer the strongest transmission channels for the spread of democracy (Figure 5a), the best-fitting statistical model (Figure 5b), the most accurate out-of-sample predictions (Figure 5c), and are not negatively correlated with alternative specifications (Figure 4). Although the "true" network structure that enables regime change to spread remains uncertain, we have ample evidence that - of the candidates considered - alliances provide the closest approximation.

Beyond statistical and predictive power, a no less important consideration is the theoretical nar- 
rative implied by each proximity measure. To investigate the empirical implications of the theory behind each of the three specifications, we conducted a simulation study of the 2011 Arab Spring.

\section{Step 3: Simulation of the 2011 Arab Spring}

The cascade of popular protests and uprisings that began to grip the Arab world in December 2010 has spawned renewed academic and public debate about the potential spread of revolutionary change. Two positions have emerged on the topic. The first expects the demonstration effect of events in Tunisia and Egypt to spark a wave of political change across the Middle East and other regions dominated by long-serving autocratic leaders (Lynch, 2011; Smith et al., 2011). The second view is more skeptical, and expects the probability of regime change to be driven less by contagion and more by exogenous factors like food price shocks and the idiosyncrasies of political institutions in individual states (Walt, 2011b,a). The differing expectations of the virulence and transmissibility of these revolutions stem in part from different views of the networks by which regime change is likely to spread. In addition to Gleditsch and Ward (2006)'s contention that this process is facilitated by cross-border movements $\left(G E O_{C O N T}\right)$, our analysis of alternatives in Step 2 has identified three other theoretical pathways as likely given the data: political communication between capital cities $\left(G E O_{K N N 4}\right)$, socialization of elites through intergovernmental organizations $\left(I G O_{K N N 4}\right)$, and military alliances (Alliance). Each network potentially yields a different set of predictions about the strength and extent of revolutionary spread.

Although the ultimate outcomes of political reforms in Tunisia and Egypt remain uncertain at the time of writing, the Arab Spring offers a fitting opportunity to apply the democratic diffusion model to a specific case. As a hypothetical scenario, we will assume that Tunisia and Egypt complete their transitions to a consolidated democracy - defined by the Polity IV characteristics of executive recruitment, constraints on executive authority, and political competition (Jaggers and Gurr, 1995). We may illustrate how our theories expect this event to resonate by answering the following question: If a democratic transition takes place in country $i$, what is the change in predicted probability of a democratic transition in country $j$ (country $i$ 's neighbor) given network specification $m$ ? This statistic is called the equilibrium effect of a democratic transition, or formally:

$$
\operatorname{Pr}\left(y_{j, t} \mid y_{i, t}=y_{i, t-1}, \mathbf{C}_{m}\right)-\operatorname{Pr}\left(y_{j, t} \mid y_{i, t} \neq y_{i, t-1}, \mathbf{C}_{m}\right)
$$

where $y_{i, t}=0$ if country $i$ is a democracy at time $t, y_{i, t}=1$ if it is an autocracy, and $C_{m}$ is the graph associated with theory $m$. All other covariates are held at their observed values.

Figure 6

Figure 6 shows predicted changes in probability of a transition from autocracy to democracy, given the establishment of democratic regimes in Tunisia and Egypt. ${ }^{21}$ Positive changes in probability indicate that regimes become more unstable and thus more likely to democratize. Only sta-

\footnotetext{
${ }^{21}$ Colors represent average changes in predicted transition probability after 1,000 simulations.
} 
tistically significant changes in probability are reported; where the $95 \%$ confidence interval around an equilibrium effect covers zero, the effect is not visualized.

Table 1

The general finding from these simulations is that democratic regime change in Tunisia and Egypt increases the probability of regime transitions in neighboring autocratic states. Each set of connectivities, however, conveys a slightly different story. With Gleditsch and Ward (2006)'s geographic contiguity neighbors, the effect reaches eight countries: Algeria, Chad, Jordan, Lebanon, Libya, Saudi Arabia, Sudan and Syria. The greatest change (+.09) takes place in Libya due to that country's direct contiguity to both Egypt and Tunisia. Democratic regime change in these countries raises the proportion of democracies in Libya's neighborhood (Algeria, Chad, Egypt, Greece, Italy, Niger, Sudan, Tunisia) from one quarter to one half. If shared borders facilitate the flow of information about democratic reforms, it will be difficult for Libya to insulate itself from changes next door. Saudi Arabia, meanwhile, experiences the lowest change in probability $(+0.027)$ due to the Kingdom's relative isolation from revolutionary events. Of the two democratizing countries, only Egypt is sufficiently proximate to exert a direct impact on Saudi domestic politics. Of the seventeen countries that share a border with Saudi Arabia or lie within $500 \mathrm{~km}$ of one, democracies remain a small minority: Egypt, Israel and Turkey, against fourteen non-democratic states.

Inter-capital distance ( $k=4$ nearest neighbors) indicates a sharper, but more geographically narrow impact. The probability of democratization rises in three North African countries: Algeria $(+.06)$, Libya $(+.07)$ and Morocco $(+.06)$. No countries east of Egypt are affected by the Arab Spring due in part to the asymmetrical logic of $k$-nearest neighbors. While each state has four incoming ties (closest neighbors of country $i$ ), the number of outgoing ties is variable (countries that count $i$ among their closest neighbors). Due to the high density of capital cities east of the Sinai peninsula, not a single Middle Eastern state counts Egypt among its four closest neighbors. Nicosia, Jerusalem, Beirut and Damascus are all closer to Amman than Cairo is, just as Baghdad, Kuwait City, Doha and Abu Dhabi are all closer to Riyadh. As a result, Egypt's democratic shift seemingly occurs in a vacuum, without any regional effect. Tunisia, by contrast, has a much stronger impact. It is an intercapital neighbor to four countries (Algeria, Italy, Libya and Morocco), three of which are autocracies where the neighborhood shock is directly felt.

Connections through intergovernmental organizations imply a broader and more varied regional impact. Because the nearest neighbor relation is not a symmetric one, many relationships are not reciprocated. Unlike in the inter-capital distance case, however, the $I G O_{K N N 4}$ definition assigns a far more central role to Egypt and Tunisia due to their levels of activity in international organizations. Seventeen countries count Egypt among the four states with which they co-participate the most in IGO's, and eleven countries list Tunisia among their top four. The effect is strongest in the countries directly connected to both newly-democratic regimes, such as Yemen $(+.14)$, Algeria $(+.13)$, Sudan $(+.12)$ and Syria $(+.11)$. It is weaker in Saudi Arabia $(+.05)$, which is connected only to Egypt, and Mauritania (+.05), which is connected only to Tunisia. 
Alliance relationships predict that democratization in Tunisia and Egypt will have a more even, but relatively diffuse effect on the region. Both countries enjoy alliance ties with the same sixteen states - Algeria, Djibouti, Iraq, Jordan, Kuwait, Lebanon, Libya, Mauritania, Morocco, Oman, Qatar, Saudi Arabia, Somalia, Sudan, Syria, and the United Arab Emirates. Unlike in the nearest neighbor specification, alliance ties are all reciprocated. Because of the dense-but-symmetric nature of the alliance network, the regional impact of the Arab Spring scenario is relatively small on average, with little variance - the increase in probability of democratization ranges between +.04 and +.05 for all neighbors.

What networks provide the most efficient channels for the Arab Spring to spread? Given the history of democratization since 1875, three specifications have shown themselves to be the most likely pathways of democratic diffusion: intercapital distance ( $k=4$ nearest neighbors), joint participation in IGO's ( $k=4$ nearest neighbors) and alliance relationships. Compared with border contiguity - the original choice of Gleditsch and Ward (2006) - these specifications yield stronger and more significant diffusion effects, tighter model fit and more accurate out-of-sample predictions. They also produce noticeably different forecasts of how democracy is likely to spread through the Arab world. In the least-likely scenario that democratic signals are transmitted by cross-border movement, transitions in Tunisia and Egypt are predicted to have the strongest impact on Libya and a more muted effect on other countries in the region. If democratic signals are transmitted by political communication between capital cities, the regional effect is predicted to be sharper but geographically confined to North Africa. If we accept the narrative that diffusion occurs through international socialization, the Arab Spring is predicted to have a broad destabilizing impact on autocratic regimes in the region, particularly where intergovernmental ties with Tunisia and Egypt are multifaceted and robust - like Yemen and Algeria. Finally, in the statistically most-likely case that democratization spreads through alliance ties, the predicted changes are more conservative in size but rather broad in geographical scope.

\section{Conclusion}

Diffusion is the study of how a phenomenon spreads, across time and space, from a point of origin to proximate locations. In modeling this process, we must specify a structure of spatial interdependence. The "true" network of diffusion, however, is typically unobserved and the choice we make will not necessarily correspond to reality. The space between objects may be geographic or non-geographic, and the signals transmitted may be physical (e.g. refugees, weapons, migrants) or more intangible (e.g. norms, policies). These networks may overlap to varying degrees, and it can be difficult to assess which measures are structurally closest to the "true" connective topology. In this paper, we offer a more systematic overview of the assumptions behind these choices, and propose a procedure to adjudicate between them.

Rather than to select an arbitrary network specification ex ante (the current norm), our pre- 
scription relies on a theoretically-informed enumeration of multiple candidates, followed by an $e x$ post evaluation of their structural similarity and relative statistical and predictive performance. We stress that, while statistical screening can help eliminate poor choices, theoretical screening should arbitrate between good ones. Using a famous model of democratic diffusion, we illustrate how disaggregated simulation and counterfactual analysis can be used to unpack the empirical implications of alternative theoretical narratives in the case of the 2011 Arab Spring. While alliance and intergovernmental ties outperformed geographic ones in our analysis, we sought to provide enough information for the reader to make their own choice.

Spatial analysis is rapidly growing in prominence in political science. At the same time, models are becoming increasingly sophisticated to adapt to quantities of particular interest to political science. ${ }^{22}$ In all uses of spatial variables, from simple controls to more complex models of contagion, we should not leave unchallenged basic assumptions about who these neighbors are and how they affect each other.

\section{Appendix: Gleditsch and Ward's empirical model}

Gleditsch and Ward (2006) examine changes of political regime as a first-order Markov chain process with the transition matrix

$$
\mathbf{K}=\left(\begin{array}{cc}
\operatorname{Pr}\left(y_{i, t}=0 \mid y_{i, t-1}=0\right) & \operatorname{Pr}\left(y_{i, t}=1 \mid y_{i, t-1}=0\right) \\
\operatorname{Pr}\left(y_{i, t}=0 \mid y_{i, t-1}=1\right) & \operatorname{Pr}\left(y_{i, t}=1 \mid y_{i, t-1}=1\right)
\end{array}\right)=\left(\begin{array}{cc}
\operatorname{Pr}(D \rightarrow D) & \operatorname{Pr}(D \rightarrow A) \\
\operatorname{Pr}(A \rightarrow D) & \operatorname{Pr}(A \rightarrow A)
\end{array}\right)
$$

where $y_{i, t}=1$ if an autocratic regime exists in country $i$ at time $t(A), y_{i, t}=0$ if the regime is democratic $(D)$, and " $\rightarrow$ " is a symbol indicating a transition from one type of regime to another between $t-1$ and $t$. Conditional transition probabilities are estimated by a probit link:

$$
\operatorname{Pr}\left(y_{i, t}=1 \mid y_{i, t-1}, \mathbf{x}_{i, t}\right)=\Phi\left[\mathbf{x}_{i, t}^{T} \beta+y_{i, t-1} \mathbf{x}_{i, t}^{T} \alpha\right]
$$

where $\mathbf{x}_{i, t}$ is the vector of covariates of interest. ${ }^{23}$ If $y_{i, t-1}=0$ (democracy), then the marginal effect of $\mathbf{x}$ on $\operatorname{Pr}\left(y_{i, t}=1\right)$ (autocracy) is $\beta$. If $y_{i, t-1}=1$ (autocracy), then the marginal effect is $\gamma$, the sum of $\beta$ and the corresponding $\alpha$ coefficient (i.e., the interactive term). ${ }^{24}$

The authors define a country's neighborhood through border contiguity, where the connectivity condition is met if at least one point on the boundary of state $j \neq i$ is either directly contiguous to

\footnotetext{
${ }^{22}$ See Franzese and Hays (2008) and Neumayer and Plümper (2010) for some of the recent, sophisticated spatial analysis techniques in political science.

${ }^{23}$ These include (in Model 1) domestic variables such as lagged GDP/capita (natural log), GDP growth, civil war and years of peace, and regional factors such as the proportion of neighboring democracies, global proportion of democracies and neighboring transitions to democracy.

${ }^{24}$ This model choice draws heavily on Przeworski and Limongi (1997), who also examine democratic transitions as a Markov process and estimate transition probabilities through a probit link, following Amemiya (1985).
} 
country $i$, or is located within a radius of $500 \mathrm{~km} .{ }^{25}$ This proximity measure is used to derive two spatial variables, both of which we re-estimated using several alternative network specifications:

1. The proportion of neighboring democracies, coded $p n b d e m_{i j}=w_{i j}\left(1-y_{j}\right)$, where $w_{i j}$ is an element of a row-standardized spatial weights matrix $\mathbf{W}$ and $y_{j}$ is the same binary autocracy variable baut for country $j$, such that $j \neq i$. This is an example of a competitive spatial weight, where the row-standardization of $\mathbf{W}$ dilutes the effect of any one country as the number of neighbors increases. ${ }^{26}$

2. Neighboring transitions to democracy, coded $n b t d_{i, t}=1$ if at least one of the neighbors of country $i$ has undergone a transition from $y_{i}=1$ (autocracy) at time $t-1$ to $y_{i}=0$ (democracy) at time $t$, and $n b t d_{i, t}=0$ otherwise. More formally,

$$
n b t d_{i, t}=\left\{\begin{array}{ll}
1 & \text { if } w_{i j} \text { demtr }_{j, t}>0 \\
0 & \text { if } w_{i j} \operatorname{demtr}_{j, t}=0
\end{array}, \text { where demtr } \text { dem, }_{j, t}= \begin{cases}1 & \text { if } y_{j, t}-y_{j, t-1}=-1 \\
0 & \text { otherwise }\end{cases}\right.
$$

This is an example of a cumulative spatial weight. Unlike in the previous variable, where only the proportion of the neighborhood mattered, each individual country's transition contributes independently of others' occurring in that time period.

\footnotetext{
${ }^{25}$ The authors use boundary-to-boundary distances from the Gleditsch and Ward (2001) Minimum Distance Dataset. Since most scholars are familiar with the Correlates of War data it is worth contrasting the two data sources. The Gleditsch and Ward (2001) Minimum Distance data provides the actual distance between states rather than the coarsened levels of the Correlates of War data. This provides the scholar with the freedom to choose their own distance thresholds.

${ }^{26}$ See Plümper and Neumayer (2010) for a detailed discussion of how row-standardization can influence model results.
} 


\section{References}

Amemiya, T. (1985). Advanced Econometrics. Cambridge, MA: Harvard University Press.

Anselin, L. (2002). Under the hood Issues in the specification and interpretation of spatial regression models . Agricultural Economics 27, 247-267.

Avis, D. and J. Horton (1985). Remarks on the Sphere of Influence Graph. Annals of the New York Academy of Sciences 440, 323-27.

Bach, D. and A. L. Newman (2010). Transgovernmental Networks and Domestic Policy Convergence: Evidence from Insider Trading Regulation. International Organization 64(03), 505-528.

Barbieri, Katherine, O. M. G. K. and B. Pollins (2009). TRADING DATA: Evaluating our Assumptions and Coding Rules. Conflict Management and Peace Science 26(5).

Barkley, D. (2008). Ballistic Missile Proliferation: An Empirical Investigation. Journal of Conflict Resolution 52(3).

Bavaud, F. (1998). Models for Spatial Weights: A Systematic Look. Geographical Analysis 30, $153-171$.

Beck, N., K. S. Gleditsch, and K. Beardsley (2006). Space Is More than Geography: Using Spatial Econometrics in the Study of Political Economy. International Studies Quarterly 50.

Beck, N., G. King, and L. Zeng (2000). Improving Quantitative Studies of International Conflict: A Conjecture. American Political Science Review 94(1), 21-36.

Bhattacharjee, A. and C. Jensen-Butler (2005, Dec). Estimation of Spatial Weights Matrix in a Spatial Error Model, with an Application to Diffusion in Housing Demand. CRIEFF Discussion Papers 0519, Centre for Research into Industry, Enterprise, Finance and the Firm.

Bivand, R. S., E. J. Pebesma, and V. Gómez-Rubio (2008). Applied Spatial Data Analysis with R. New York: Springer.

Buhaug, H. and K. S. Gleditsch (2008). Contagion or Confusion? Why Conflicts Cluster in Space. International Studies Quarterly 52.

Butts, C. and K. Carley (2001). Multivariate Methods for Interstructural Analysis.

Butts, C. and K. Carley (2005). Some Simple Algorithms for Structural Comparison. Computational and Mathematical Organization Theory 11.

Cao, X. (2009, Dec). Networks of Intergovernmental Organizations and Convergence in Domestic Economic Policies. International Studies Quarterly 53(4), 1095-1130.

Cao, X. (2010). Networks as Channels of Policy Diffusion: Explaining Worldwide Changes in Capital Taxation, 1998-2006. International Studies Quarterly 54(3).

Chiozza, G. (2002). Is There a Clash of Civilizations? Evidence from Patterns of International Conflict Involvement, 194697. Journal of Peace Research 39(6).

Clark, D. H. and P. M. Regan (2003). Opportunities to Fight. A Statistical Technique for Modeling Unobservable Phenomena. Journal of Conflict Resolution 47(1).

Dorussen, H. (2006). Heterogeneous Trade Interests and Conflict: What You Trade Matters. Journal of Conflict Resolution $50(1)$.

Elkins, Z., A. Guzman, and B. Simmons (2006). Competing for Capital: The Diffusion of Bilateral Investment Treaties 1960-2000. International Organization 60(4).

Ertur, C., J. L. Gallo, and J. LeSage (2007). Local versus Global Convergence in Europe: A Bayesian Spatial Econometric Approach. Review of Regional Studies 37(1). 
Fingleton, B. (2003). Externalities, Economic Geography, And Spatial Econometrics: Conceptual And Modeling Developments. International Regional Science Review 26(197).

Franzese, R. J. and J. C. Hays (2008). The Oxford Handbook of Political Methodology, Chapter Empirical Models of Spatial Interdependence. Oxford University Press.

Gartzke, E., Q. Li, and C. Boehmer (2001). Investing in the Peace: Economic Interdependence and International Conflict. International Organization 55(2).

Gelman, A. and F. Tuerlinckx (2000). Type s error rates for classical and bayesian single and multiple comparison procedures. Computational Statistics 15, 373-390.

Gibler, D. M. and M. Sarkees (2004). Measuring Alliances: The Correlates of War Formal Interstate Alliance Data set, 1816-2000. Journal of Peace Research 41(2).

Gleditsch, K. S., I. Salehyan, and K. Schultz (2008). Fighting at Home, Fighting Abroad: How Civil Wars Lead to International Disputes. Journal of Conflict Resolution 52(4).

Gleditsch, K. S. and M. Ward (2001). Measuring Space: A Minimum-Distance Database and Applications to International Studies. Journal of Peace Research 30(6), 749-68.

Gleditsch, K. S. and M. D. Ward (2000). War and Peace in Space and Time: The Role of Democratization. International Studies Quarterly 44.

Gleditsch, K. S. and M. D. Ward (2006, Fall). Diffusion and the International Context of Democratization. International Organization 60, 911-33.

Gleditsch, K. S. and M. D. Ward (2007, June). An Introduction to Spatial Regression Models in the Social Sciences.

Goldstein, J., D. Rivers, and M. Tomz (2007). Institutions in International Relations: Understanding the Effects of the GATT and the WTO on Trade. International Organization 61(1).

Gowa, J. and E. Mansfield (2004). Alliances, Imperfect Markets and Major-Power Trade. International Organization 58(4).

Greenhill, B. (2010). The Company You Keep: International Socialization and the Diffusion of Human Rights Norms. International Studies Quarterly 54(1), 127-145.

Greenhill, B., L. Mosley, and A. Prakash (2009). Trade-based Diffusion of Labor Rights: A Panel Study, $1986-2002$. American Political Science Review 103(04), 669-690.

Hafner-Burton, E., M. Kahler, and A. H. Montgomery (2009). Network Analysis For International Relations. International Organization 63(1), 559-92.

Hammarstrom, M. and B. Heldt (2002, Oct-Dec). The diffusion of military intervention: Testing a network position approach. International Interactions 28(4), 355-377.

Holloway, G. and M. Lapar (2007). How big is your neighbourhood? Spatial implications of market participation among Filipino smallholders. Journal of Agricultural Economics 58, 37-60.

Jaggers, K. and T. R. Gurr (1995). Tracking Democracy's Third Wave with the Polity II Data. Journal of Peace Research 32(4), 469-82.

Keohane, R. O. (1988). International Institutions: Two Approaches. International Studies Quarterly 32.

Kooijman, S. (1976). Some remarks on the statistical analysis of grids especially with respect to ecology. Annals of Systems Research 5, 113-132.

Kostov, P. (2010). Model boosting for spatial weighting matrix selection in spatial lag models. Environment and Planning B: Planning and Design 37, 533-549. 
Krackhardt, D. (1987). Cognitive Social Structures. Social Networks 9.

Krackhardt, D. (1988). Predicting With Networks: Nonparametric Multiple Regression Analyses of Dyadic Data. Social Networks 10.

Krustev, V. (2006). Interdependence and the Duration of Militarized Conflict. Journal of Peace Research 43(3).

Lazer, D. (2011). Networks in Political Science: Back to the Future. PS: Political Science E Politics 44(01), 61-68.

Lee, C. K. and D. Strang (2006). The international diffusion of public-sector downsizing: Network emulation and theory-driven learning. International Organization 60(4).

Lee, S.-Y. (2009). Bias from Misspecified Spatial Weight Matrices in SAR Models: Theory and Simulation Studies . Department of Economics, San Francisco State University.

Leeds, B. A. (2003). Do Alliances Deter Aggresion? The Influence of Military Alliances on the Initation of Militarized Interstate Disputes. American Journal of Political Science $47(3)$.

Leeson, P. T. and A. M. Dean (2009). The Democratic Domino Theory: An Empirical Investigation. American Journal of Political Science 53(3).

Lemke, D. and W. Reed (2001). War and Rivalry among Great Powers. American Journal of Political Science 45(2).

LeSage, J. P. and O. Parent (2007). Bayesian model averaging for spatial econometric models. Geographical Analysis 39, 241-267.

Lynch, M. (2011, January). Arab regimes on edge. Foreign Policy.

McPherson, M., L. Smith-Lovin, and J. M. Cook (2001). Birds of a Feather: Homophily in Social Networks. Annual Review of Sociology 27.

Murdoch, J. C. and T. Sandler (2002, February). Economic Growth, Civil Wars, and Spatial Spillovers. Journal of Conflict Resolution.

Neumayer, E. and T. Plümper (2010). Spatial effects in dyadic data. International Organization 64, $145-66$.

O'Loughlin, J. and L. Anselin (1991). Bringing Geography Back to the Study of International Relations: Spatial Dependence and Regional Context in Africa, 1966-1978. International Interactions 17(1), 29-61.

O’Loughlin, J., M. D. Ward, C. L. Lofdahl, J. S. Cohen, D. S. Brown, D. Reilly, K. S. Gleditsch, and M. Shin (1998). The diffusion of democracy, 1946-1994. Annals of the Association of the American Geographers 88(4), 545-574.

Pevehouse, J. (2002). Democracy from the Outside-In? International Organizations and Democratization. International Organization 56(3).

Pevehouse, Jon C., T. N. and K. Warnke (2004). The COW-2 International Organizations Dataset Version 2.0. Conflict Management and Peace Science 21(2).

Plümper, T. and E. Neumayer (2010). Model specification in the analysis of spatial dependence. European Journal of Political Research 49(3), 418-442.

Przeworski, A. and F. Limongi (1997, January). Modernization: Theories and Facts. World Politics 49, $155-83$.

Rasler, K. and W. R. Thompson (2006). Contested Territory, Strategic Rivalries and Conflict Escalation. International Studies Quarterly 50(1), 145-167.

Reiter, D. and A. Stam (2003). Identifying the Culprit: Democracy, Dictatorship, and Dispute Initiation. American Political Science Review $97(2)$.

Salehyan, I. (2008). The Externalities of Civil Strife: Refugees as a Source of International Conflict. American Journal of Political Science 52(4). 
Salehyan, I. and K. S. Gleditsch (2006). Refugees and the Spread of Civil War. International Organization 60(2).

Seldadyo, H., J. P. Elhorst, and J. De Haan (2010, Aug). Geography and governance: Does space matter? Papers in Regional Science 89(3), 625-640.

Shalizi, C. R. and A. C. Thomas (2011). Homophily and Contagion Are Generically Confounded in Observational Social Network Studies. Sociological Methods and Research 40.

Simmons, B. and Z. Elkins (2004). The Globalization of Liberalization: Policy Diffusion in the International Political Economy. American Political Science Review 98(1).

Simmons, B. A. and L. L. Martin (2001). Handbook of International Relations, Chapter International Organizations and Institutions, pp. 191-211. Sage.

Siverson, R. M. and H. Starr (1991). The Diffusion of War: A Study of Opportunity and Willingness. Ann Arbor: The University of Michigan Press.

Slantchev, B. (2004). How Initiators End Their Wars: The Duration of Warfare and the Terms of Peace. American Journal of Political Science 48(4).

Smith, D., P. Allen, and N. Rojas (2011, April). Will the Arab Spring spread south? The Guardian.

Starr, H. (1991). Democratic dominos: Diffusion approaches to the spread of democracy in the international system. Journal of Conflict Resolution 35, 356-81.

Starr, H. and C. Lindborg (2003). Democratic Dominoes Revisited. The Hazards of Governmental Transitions, 1974-1996. Journal of Conflict Resolution 47(4).

Starr, H. and G. D. Thomas (2005). The Nature of Borders and International Conflict: Revisiting Hypotheses on Territory. International Studies Quarterly 49.

Stetzer, F. (1982). Specifying Weights in Spatial Forecasting Models: The Results of Some Experiments. Environment and Planning 14(5), 571-84.

Stinnett, D. M., J. Tir, P. Schafer, P. F. Diehl, and C. Gochman (2002). The Correlates of War Project Direct Contiguity Data, version 3. Conflict management and Peace Science 19(2), 58-66.

Strebel, F. (2011, Jan). Inter-governmental institutions as promoters of energy policy diffusion in a federal setting. Energy Policy 39(1), 467-476.

Thomas, A. C. and J. K. Blitzstein (2009a, 23 October). The Effect of Censoring Out-Degree On Network Inferences.

Thomas, A. C. and J. K. Blitzstein (2009b, 24 October). The Thresholding Problem: Uncertainties Due to Dichotomization of Valued Ties.

Tobler, W. (1970). A Computer Movie Simulating Urban Growth in the Detroit Region. Economic Geography 46, $234-240$.

Walt, S. M. (2011a, March). A Short-Lived Arab Spring? Foreign Policy.

Walt, S. M. (2011b, January). Why the Tunisian Revolution won't spead. Foreign Policy.

Ward, M., B. Greenhill, and K. Bakke (2010). The perils of policy by p-value: Predicting civil conflicts. Journal of Peace Research 47(4).

Weidmann, N. B., D. Kuse, and K. S. Gleditsch (2010). The geography of the international system: The cshapes dataset. International Interactions 36, 1.

Weidmann, N. B., J. K. Rd, and L.-E. Cederman (2010). Representing Ethnic Groups in Space: A New Dataset. Journal of Peace Research $47(4)$. 


\section{Tables}

Table 1: Arab Spring Simulation: Effect of Democratic Transition in Egypt and Tunisia. Numbers report increase in probability of a democratic transition in country $j$ at time $t$, given a democratic transition in Tunisia and Egypt at time $t-1$. All other variables are held constant at their median levels. Statistics are averaged over 1,000 simulations. Only statistically significant changes reported (where $95 \%$ confidence interval does not cover zero).

\begin{tabular}{|c|c|c|c|c|c|c|c|c|c|c|c|c|c|c|}
\hline Country & 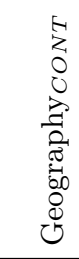 & 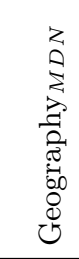 & 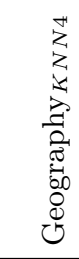 & 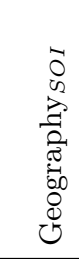 & 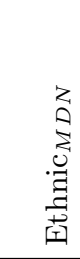 & 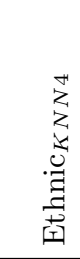 & 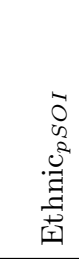 & 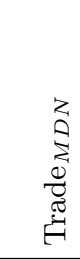 & 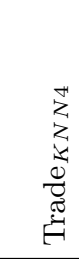 & 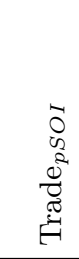 & $\begin{array}{l}z \\
\vdots \\
\vdots \\
\vdots \\
\vdots \\
\vdots\end{array}$ & 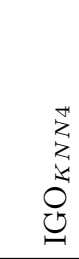 & $\begin{array}{l}0 \\
0 \\
0 \\
0 \\
0 \\
0\end{array}$ & 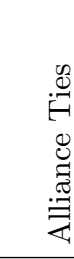 \\
\hline Algeria & 0.04 & 0.02 & 0.06 & 0.07 & 0.00 & 0.00 & 0.06 & 0.05 & 0.00 & 0.00 & 0.00 & 0.13 & 0.10 & 0.05 \\
\hline Armenia & 0.00 & 0.01 & 0.00 & 0.00 & 0.00 & 0.00 & 0.00 & 0.00 & 0.00 & 0.00 & 0.00 & 0.00 & 0.00 & 0.00 \\
\hline Azerbaijan & 0.00 & 0.01 & 0.00 & 0.00 & 0.00 & 0.00 & 0.00 & 0.00 & 0.00 & 0.00 & 0.00 & 0.00 & 0.00 & 0.00 \\
\hline Belarus & 0.00 & 0.03 & 0.00 & 0.00 & 0.00 & 0.00 & 0.00 & 0.00 & 0.00 & 0.00 & 0.00 & 0.00 & 0.00 & 0.00 \\
\hline Bosnia \& Herzegovina & 0.00 & 0.03 & 0.00 & 0.00 & 0.00 & 0.00 & 0.00 & 0.03 & 0.00 & 0.00 & 0.00 & 0.00 & 0.00 & 0.00 \\
\hline Chad & 0.03 & 0.02 & 0.00 & 0.00 & 0.00 & 0.00 & 0.00 & 0.00 & 0.00 & 0.00 & 0.00 & 0.00 & 0.00 & 0.00 \\
\hline China & 0.00 & 0.00 & 0.00 & 0.00 & 0.00 & 0.00 & 0.00 & 0.04 & 0.00 & 0.00 & 0.00 & 0.00 & 0.00 & 0.00 \\
\hline Croatia & 0.00 & 0.03 & 0.00 & 0.00 & 0.00 & 0.00 & 0.00 & 0.02 & 0.00 & 0.00 & 0.00 & 0.00 & 0.00 & 0.00 \\
\hline Cuba & 0.00 & 0.00 & 0.00 & 0.00 & 0.00 & 0.00 & 0.00 & 0.03 & 0.00 & 0.00 & 0.00 & 0.00 & 0.00 & 0.00 \\
\hline Djibouti & 0.00 & 0.01 & 0.00 & 0.00 & 0.00 & 0.00 & 0.00 & 0.00 & 0.00 & 0.00 & 0.00 & 0.05 & 0.00 & 0.05 \\
\hline Egypt & 0.00 & 0.01 & 0.00 & 0.00 & 0.00 & 0.00 & 0.00 & 0.02 & 0.00 & 0.00 & 0.00 & 0.04 & 0.07 & 0.02 \\
\hline Ethiopia & 0.00 & 0.01 & 0.00 & 0.00 & 0.00 & 0.00 & 0.00 & 0.02 & 0.00 & 0.00 & 0.00 & 0.00 & 0.00 & 0.00 \\
\hline Georgia & 0.00 & 0.01 & 0.00 & 0.00 & 0.00 & 0.00 & 0.00 & 0.00 & 0.00 & 0.00 & 0.00 & 0.00 & 0.00 & 0.00 \\
\hline Indonesia & 0.00 & 0.00 & 0.00 & 0.00 & 0.00 & 0.00 & 0.00 & 0.05 & 0.00 & 0.00 & 0.00 & 0.00 & 0.00 & 0.00 \\
\hline Iran & 0.00 & 0.01 & 0.00 & 0.00 & 0.00 & 0.00 & 0.00 & 0.02 & 0.00 & 0.00 & 0.00 & 0.08 & 0.00 & 0.00 \\
\hline Iraq & 0.00 & 0.01 & 0.00 & 0.00 & 0.00 & 0.00 & 0.00 & 0.05 & 0.00 & 0.00 & 0.00 & 0.11 & 0.14 & 0.04 \\
\hline Cote d'Ivory & 0.00 & 0.00 & 0.00 & 0.00 & 0.00 & 0.00 & 0.00 & 0.02 & 0.00 & 0.00 & 0.00 & 0.00 & 0.00 & 0.00 \\
\hline Jordan & 0.04 & 0.01 & 0.00 & 0.00 & 0.00 & 0.00 & 0.00 & 0.02 & 0.00 & 0.00 & 0.00 & 0.05 & 0.14 & 0.05 \\
\hline Kazakhstan & 0.00 & 0.00 & 0.00 & 0.00 & 0.00 & 0.00 & 0.00 & 0.02 & 0.00 & 0.00 & 0.00 & 0.00 & 0.00 & 0.00 \\
\hline Kenya & 0.00 & 0.00 & 0.00 & 0.00 & 0.00 & 0.00 & 0.00 & 0.02 & 0.00 & 0.00 & 0.00 & 0.00 & 0.00 & 0.00 \\
\hline Kuwait & 0.00 & 0.01 & 0.00 & 0.00 & 0.00 & 0.00 & 0.00 & 0.02 & 0.00 & 0.00 & 0.00 & 0.12 & 0.00 & 0.05 \\
\hline Lebanon & 0.05 & 0.03 & 0.00 & 0.00 & 0.00 & 0.07 & 0.00 & 0.03 & 0.00 & 0.00 & 0.00 & 0.14 & 0.16 & 0.05 \\
\hline Libya & 0.09 & 0.03 & 0.07 & 0.08 & 0.00 & 0.05 & 0.00 & 0.05 & 0.00 & 0.00 & 0.00 & 0.05 & 0.00 & 0.05 \\
\hline Malaysia & 0.00 & 0.00 & 0.00 & 0.00 & 0.00 & 0.00 & 0.00 & 0.05 & 0.00 & 0.00 & 0.00 & 0.00 & 0.00 & 0.00 \\
\hline Mauritania & 0.00 & 0.00 & 0.00 & 0.00 & 0.00 & 0.00 & 0.00 & 0.00 & 0.00 & 0.00 & 0.00 & 0.05 & 0.00 & 0.04 \\
\hline Morocco & 0.00 & 0.01 & 0.06 & 0.00 & 0.00 & 0.00 & 0.00 & 0.02 & 0.00 & 0.00 & 0.00 & 0.11 & 0.09 & 0.04 \\
\hline Niger & 0.00 & 0.01 & 0.00 & 0.00 & 0.00 & 0.00 & 0.00 & 0.00 & 0.00 & 0.00 & 0.00 & 0.00 & 0.00 & 0.00 \\
\hline Oman & 0.00 & 0.00 & 0.00 & 0.00 & 0.00 & 0.00 & 0.00 & 0.00 & 0.00 & 0.00 & 0.00 & 0.05 & 0.00 & 0.05 \\
\hline Qatar & 0.00 & 0.01 & 0.00 & 0.00 & 0.00 & 0.00 & 0.00 & 0.00 & 0.00 & 0.00 & 0.00 & 0.00 & 0.00 & 0.05 \\
\hline Russia & 0.00 & 0.00 & 0.00 & 0.00 & 0.00 & 0.00 & 0.00 & 0.05 & 0.00 & 0.00 & 0.00 & 0.00 & 0.00 & 0.00 \\
\hline Saudi Arabia & 0.03 & 0.01 & 0.00 & 0.00 & 0.00 & 0.00 & 0.00 & 0.05 & 0.00 & 0.00 & 0.00 & 0.05 & 0.00 & 0.05 \\
\hline Somalia & 0.00 & 0.00 & 0.00 & 0.00 & 0.00 & 0.00 & 0.00 & 0.00 & 0.00 & 0.00 & 0.00 & 0.04 & 0.00 & 0.04 \\
\hline Sri Lanka & 0.00 & 0.00 & 0.00 & 0.00 & 0.00 & 0.00 & 0.00 & 0.02 & 0.00 & 0.00 & 0.00 & 0.00 & 0.00 & 0.00 \\
\hline Sudan & 0.03 & 0.01 & 0.00 & 0.00 & 0.00 & 0.00 & 0.06 & 0.00 & 0.00 & 0.00 & 0.00 & 0.12 & 0.08 & 0.05 \\
\hline Syria & 0.03 & 0.01 & 0.00 & 0.00 & 0.00 & 0.00 & 0.00 & 0.02 & 0.00 & 0.00 & 0.00 & 0.11 & 0.13 & 0.04 \\
\hline Tunisia & 0.00 & 0.02 & 0.00 & 0.00 & 0.00 & 0.06 & 0.00 & 0.03 & 0.00 & 0.00 & 0.00 & 0.05 & 0.09 & 0.02 \\
\hline United Arab Emirates & 0.00 & 0.01 & 0.00 & 0.00 & 0.00 & 0.00 & 0.00 & 0.02 & 0.00 & 0.00 & 0.00 & 0.05 & 0.00 & 0.05 \\
\hline Yemen & 0.00 & 0.01 & 0.00 & 0.00 & 0.00 & 0.00 & 0.00 & 0.00 & 0.00 & 0.00 & 0.00 & 0.14 & 0.00 & 0.00 \\
\hline Eritrea & 0.00 & 0.01 & 0.00 & 0.00 & 0.00 & 0.05 & 0.00 & 0.00 & 0.00 & 0.00 & 0.00 & 0.00 & 0.00 & 0.00 \\
\hline Serbia & 0.00 & 0.03 & 0.00 & 0.00 & 0.00 & 0.00 & 0.00 & 0.00 & 0.00 & 0.00 & 0.00 & 0.00 & 0.00 & 0.00 \\
\hline
\end{tabular}




\section{Figure Captions}

Figure 1. Structural Similarity and Model Selection. Plots show results of Monte Carlo simulation with 1,000 random graphs. Horizontal axes in each plot display the graph correlation of each graph $\mathbf{C}_{m}$ with the true matrix $\mathbf{C}$. The vertical axes report statistics corresponding to: [1a] spatial autocorrelation parameter estimates, [1b] AIC statistics, and [1c] out-of-sample RMSE means.

Figure 2. Sphere of influence graph. Nodes represent cities, directed edges (radii of circles) correspond to nearest neighbor distances. Here, city $B$ is the nearest neighbor of city $A, B$ and $C$ are nearest neighbors of each other, and $C$ is the nearest neighbor of $D$. Where the circles around reach city overlap in at least two points, the cities can be considered neighbors. In the current example, $A$ is a neighbor of $B$ and $C$ but not $D, B$ is a neighbor of $A$ and $C, C$ is a neighbor to all, $D$ is a neighbor only of $C$.

Figure 3. Network specifications. Green lines indicate the existence of a connection between each pair of country according to each distance or proximity metric and connectivity criterion.

Figure 4. Structural similarity. Colors correspond to size and direction of graph correlation statistics for every pair of network specifications shown in Figure 3.

Figure 5. Model fit diagnostics. Figures show (a) changes in transition probability due to a single standard deviation increase above the mean in the proportion of neighboring democracies, holding all other variables at their means, (b) model AIC statistics, and (c) out-of-sample areas under the ROC curve, averaged over 100 random data partitions. Horizontal lines show $95 \%$ confidence intervals. Labels on vertical axis indicate proximity measure used in estimation of each model.

Figure 6. Arab Spring simulation. Average change in transition probability after 1,000 simulations. 


\section{Figures}

Figure 1: Structural Similarity and Model Selection. Plots show results of Monte Carlo simulation with 1,000 random graphs. Horizontal axes in each plot display the graph correlation of each graph $\mathbf{C}_{m}$ with the true matrix $\mathbf{C}$. The vertical axes report statistics corresponding to: [1a] spatial autocorrelation parameter estimates, [1b] AIC statistics, and [1c] out-of-sample RMSE means.

(a) Strength of autocorrelation

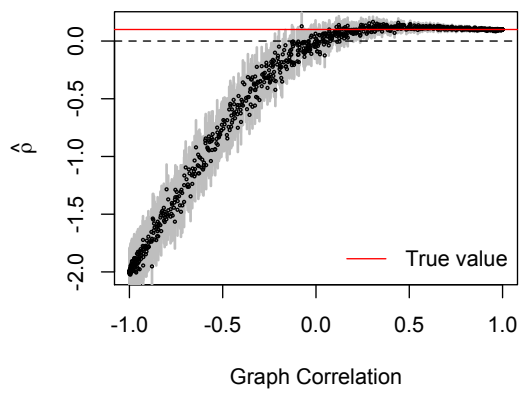

(b) Goodness-of-fit

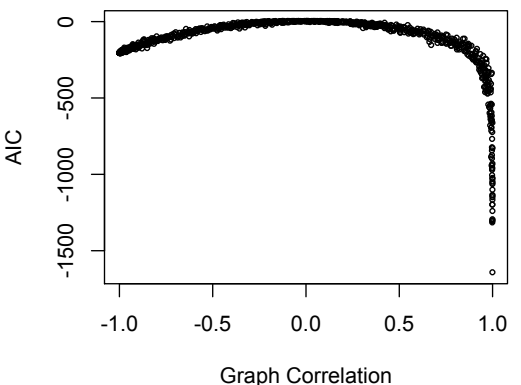

(c) Cross-validation

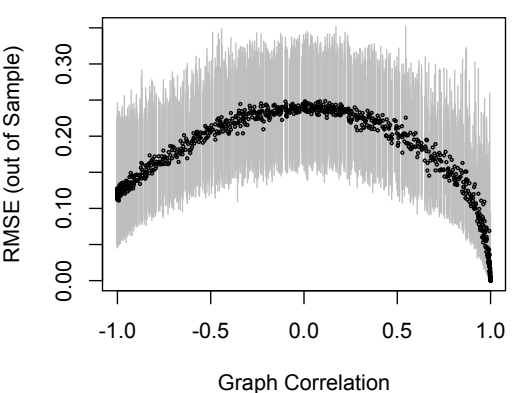

Figure 2: Sphere of influence graph. Nodes represent cities, directed edges (radii of circles) correspond to nearest neighbor distances. Here, city $B$ is the nearest neighbor of city $A, B$ and $C$ are nearest neighbors of each other, and $C$ is the nearest neighbor of $D$. Where the circles around reach city overlap in at least two points, the cities can be considered neighbors. In the current example, $A$ is a neighbor of $B$ and $C$ but not $D, B$ is a neighbor of $A$ and $C, C$ is a neighbor to all, $D$ is a neighbor only of $C$.

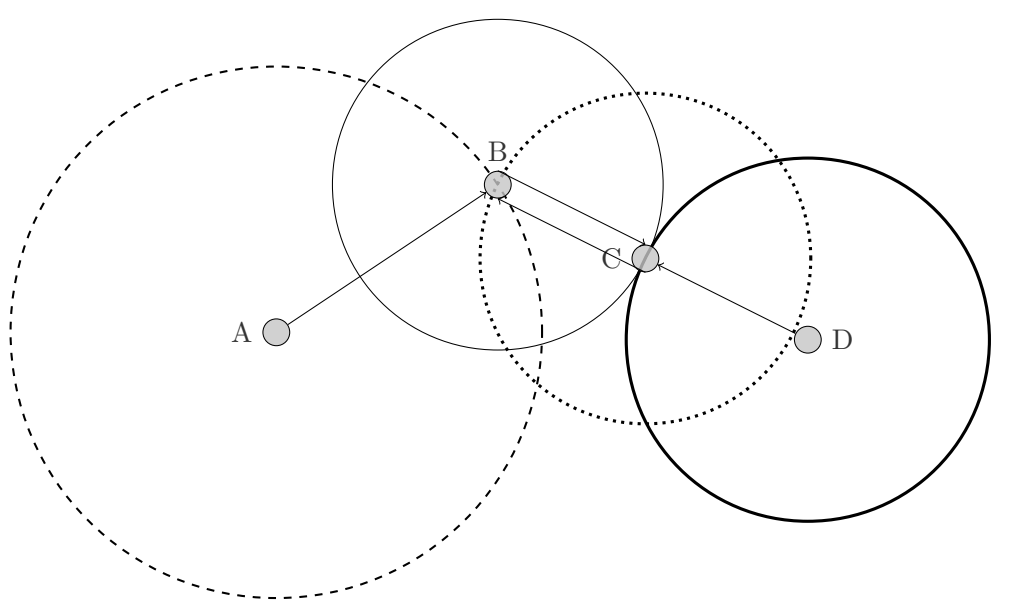


Figure 3: Network specifications. Green lines indicate the existence of a connection between each pair of country according to each distance or proximity metric and connectivity criterion.

\section{Metric}

Interborder distance

Intercapital distance

Ethnic proximity

Trade proximity

Intergovernmental proximity

Alliance proximity

\section{Connectivity Criterion}

\author{
Thresholding Minimum Distance $\quad k$-Nearest $\quad$ Sphere of Influence
}
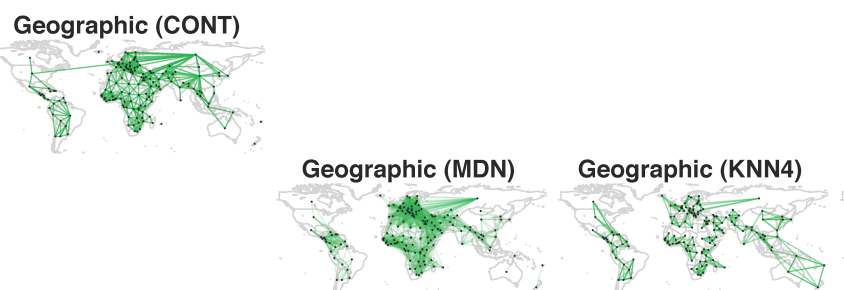

Geographic (SOI)

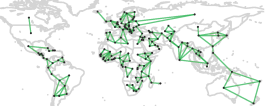

Ethnic (MDN)

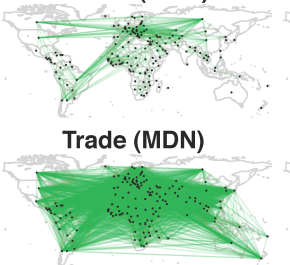

Ethnic (KNN4)

Ethnic (pSOI)

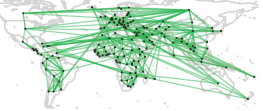

Trade (KNN4)
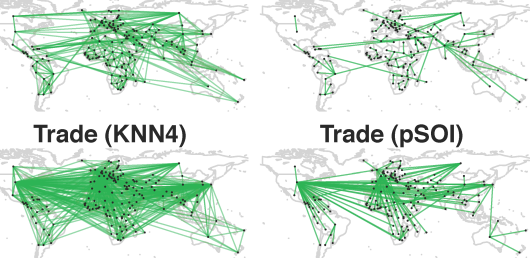

IGO (MDN)

IGO (KNN4)

IGO (pSOI)

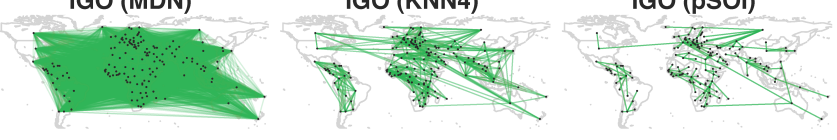


Figure 4: Structural similarity. Colors correspond to size and direction of graph correlation statistics for every pair of network specifications shown in Figure 3.

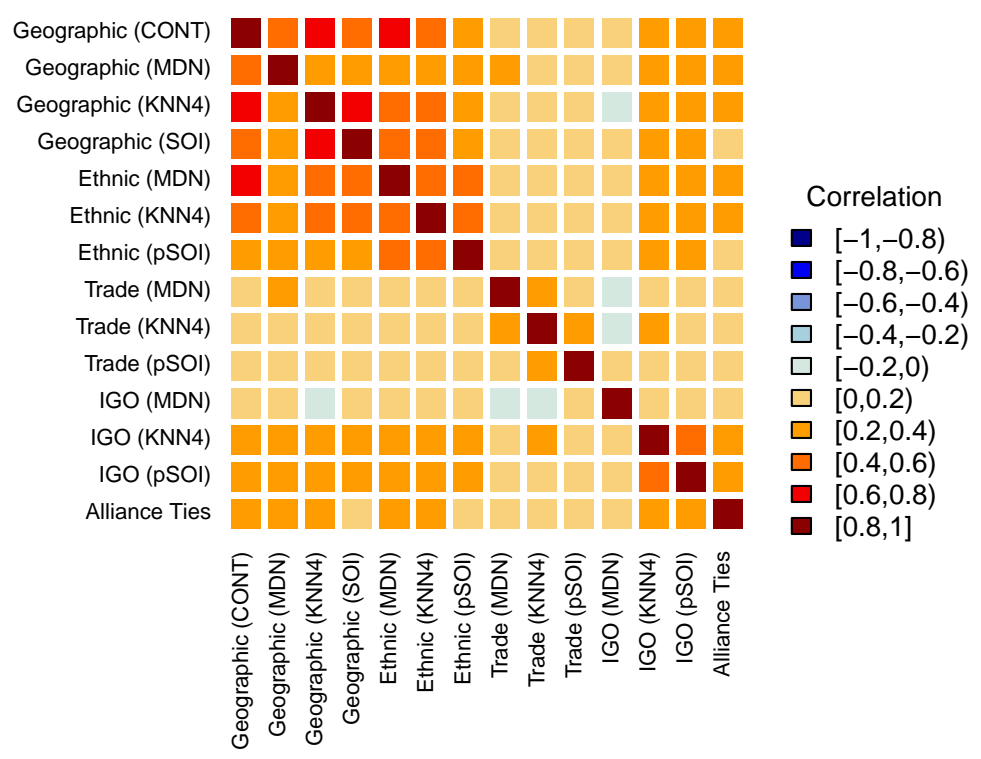

Figure 5: Model fit diagnostics. Figures show (a) changes in transition probability due to a single standard deviation increase above the mean in the proportion of neighboring democracies, holding all other variables at their means, (b) model AIC statistics, and (c) out-of-sample areas under the ROC curve, averaged over 100 random data partitions. Horizontal lines show $95 \%$ confidence intervals. Labels on vertical axis indicate proximity measure used in estimation of each model.
(a) Strength of autocorrelation
(b) Goodness-of-fit
(c) Cross validation

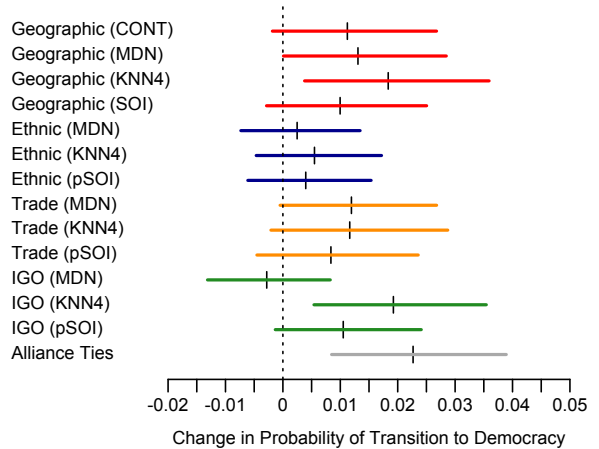

\begin{tabular}{lr} 
Geographic (CONT) & 1003.742 \\
Geographic (MDN) & 1019.262 \\
Geographic (KNN4) & 1008.093 \\
Geographic (SOI) & 1015.835 \\
Ethnic (MDN) & 1028.084 \\
Ethnic (KNN4) & 1020.232 \\
Ethnic (pSOI) & 1022.186 \\
Trade (MDN) & 1012.839 \\
Trade (KNN4) & 1014.519 \\
Trade (pSOI) & 1028.327 \\
IGO (MDN) & 1028.575 \\
IGO (KNN4) & 991.531 \\
IGO (pSOI) & 1011.105 \\
Alliance Ties & 968.697 \\
& \\
& \\
\multicolumn{2}{l}{ Akaike Information Criterion (AIC) }
\end{tabular}

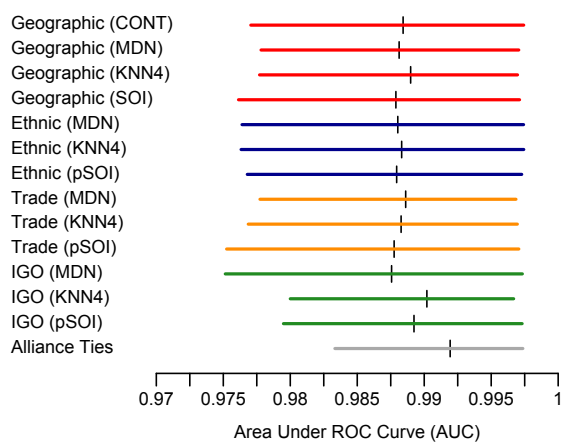


Figure 6: Arab Spring simulation. Average change in transition probability after 1,000 simulations.

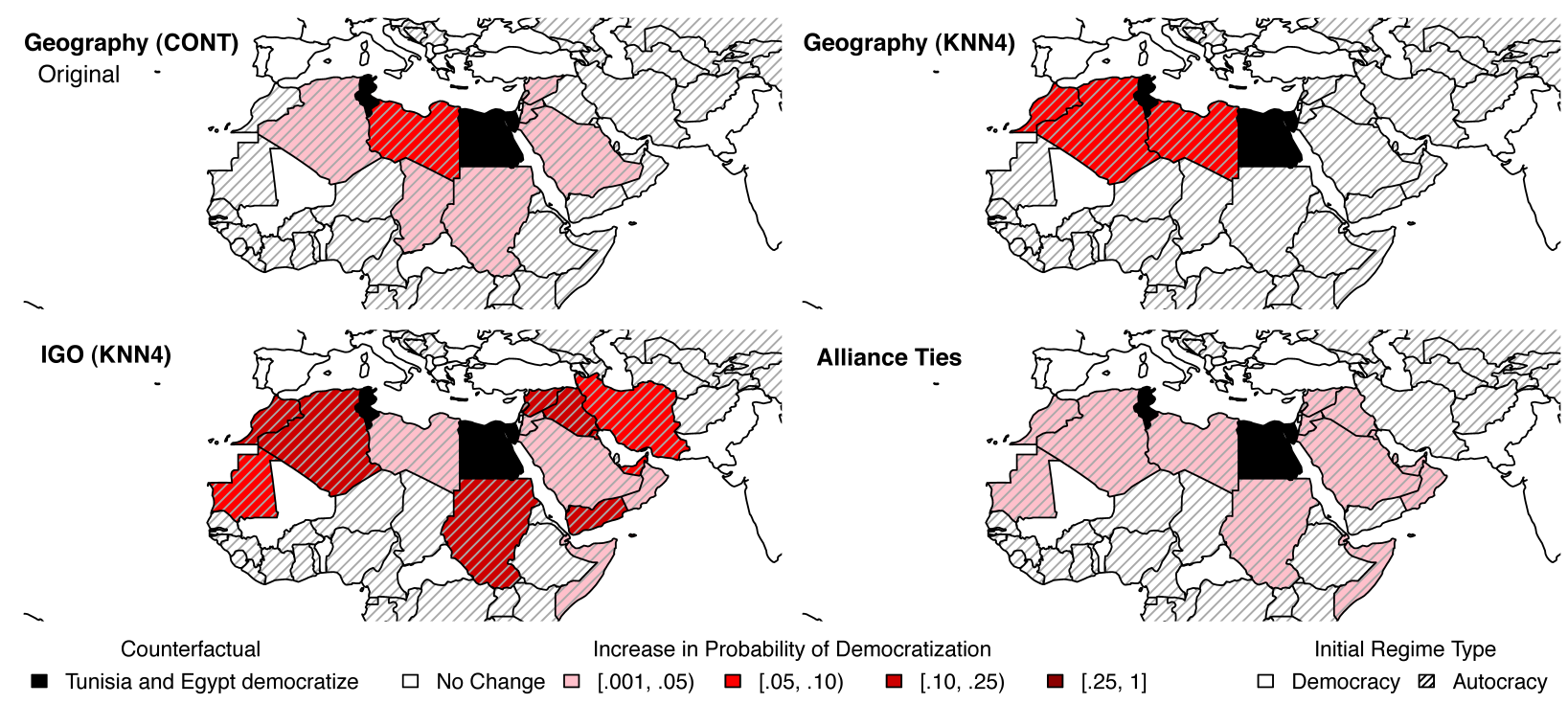

